\title{
Bacterial selection during the formation of early-stage aerobic granules in wastewater treatment systems operated under wash-out dynamics
}

\author{
David G. Weissbrodt ${ }^{1}$, Samuel Lochmatter ${ }^{1}$, Sirous Ebrahimi ${ }^{1 \dagger}$, Pierre Rossi ${ }^{2}$, Julien Maillard ${ }^{1}$ and \\ Christof Holliger ${ }^{1 *}$ \\ Laboratory for Environmental Biotechnology, School for Architecture, Civil and Environmental Engineering, Ecole Polytechnique Fédérale de Lausanne, Lausanne, \\ Switzerland \\ ${ }^{2}$ Central Environmental Molecular Biology Laboratory, School for Architecture, Civil and Environmental Engineering, Ecole Polytechnique Fédérale de Lausanne, \\ Lausanne, Switzerland
}

\section{Edited by:}

Weiwen Zhang, Tianjin University, China

\section{Reviewed by:}

Uwe Strotmann, Fachhochschule

Gelsenkirchen, Germany

Johannes Scholten, Harleysville, USA

*Correspondence:

Christof Holliger, EPFL ENAC IIE

LBE, Station 6, CH-1015 Lausanne,

Switzerland.

e-mail: christof.holliger@epfl.ch

\section{${ }^{\dagger}$ Present address:}

Sirous Ebrahimi, Sahand University of Technology, Chemical Engineering Faculty, Tabriz, Iran
Aerobic granular sludge is attractive for high-rate biological wastewater treatment. Biomass wash-out conditions stimulate the formation of aerobic granules. Deteriorated performances in biomass settling and nutrient removal during start-up have however often been reported. The effect of wash-out dynamics was investigated on bacterial selection, biomass settling behavior, and metabolic activities during the formation of early-stage granules from activated sludge of two wastewater treatment plants (WWTP) over start-up periods of maximum 60 days. Five bubble-column sequencing batch reactors were operated with feast-famine regimes consisting of rapid pulse or slow anaerobic feeding followed by aerobic starvation. Slow-settling fluffy granules were formed when an insufficient superficial air velocity (SAV; $1.8 \mathrm{~cm} \mathrm{~s}^{-1}$ ) was applied, when the inoculation sludge was taken from a WWTP removing organic matter only, or when reactors were operated at $30^{\circ} \mathrm{C}$. Fast-settling dense granules were obtained with $4.0 \mathrm{~cm} \mathrm{~s}^{-1} \mathrm{SAV}$, or when the inoculation sludge was taken from a WWTP removing all nutrients biologically. However, only carbon was aerobically removed during start-up. Fluffy granules and dense granules were displaying distinct predominant phylotypes, namely filamentous Burkholderiales affiliates and Zoogloea relatives, respectively. The latter were predominant in dense granules independently from the feeding regime. A combination of insufficient solid retention time and of leakage of acetate into the aeration phase during intensive biomass wash-out was the cause for the proliferation of Zoogloea spp. in dense granules, and for the deterioration of BNR performances. It is however not certain that Zoogloea-like organisms are essential in granule formation. Optimal operation conditions should be elucidated for maintaining a balance between organisms with granulation propensity and nutrient removing organisms in order to form granules with BNR activities in short start-up periods.

Keywords: biological wastewater treatment, aerobic granular sludge, granule formation, wash-out dynamics, bacterial selection, nutrient removal limitations

\section{INTRODUCTION}

Aerobic granular sludge (AGS) wastewater treatment processes are attractive for intensive and high-rate biological nutrient removal (BNR) and secondary clarification in single sequencing batch reactors (SBR; de Bruin et al., 2004; Giesen et al., 2012). Stable dense and fast-settling aerobic granules with tailored metabolic activities for the removal of carbon, nitrogen, and phosphorus are desired for the operation of robust AGS wastewater treatment plants (WWTP). For instance, the overgrowth of filamentous organisms must be avoided in order to prevent process disturbances by the deterioration of the settling properties of aerobic granules (van Loosdrecht et al., 2008).

The formation of aerobic granules has been stimulated by reactor start-up conditions leading to the wash-out of flocculent biomass and selecting for a fast-settling biomass, namely with the combination of short settling times of $3-5 \mathrm{~min}$ and short hydraulic retention times (HRT) of $6 \mathrm{~h}$ (Beun et al., 1999). Granulation can be impacted by additional operation parameters such as the influent feeding regime, the hydrodynamic shear force, and the concentration of dissolved oxygen (DO). For a review, refer to Lee et al. (2010). Granules have been successfully cultivated with feast-famine regimes involving pulse feeding $(3-5 \mathrm{~min})$ followed by prolonged aeration (3-4 h; Morgenroth et al., 1997; Beun et al., 1999; Tay et al., 2002), or anaerobic feeding ( $1 \mathrm{~h}$ ) followed by aerobic starvation (2 h; de Kreuk et al., 2005). Granulation has only been observed with up-flow superficial air velocities (SAV) above $0.010 \mathrm{~m} \mathrm{~s}^{-1}$, typically between 0.025 and $0.045 \mathrm{~m} \mathrm{~s}^{-1}$. High upflow aeration induce high shear and compaction forces at the surface of granules (Zima et al., 2007), and stimulate the production of exopolymeric substances (EPS) as well as hydrophobic 
adhesive interactions (Liu and Tay, 2002; Dulekgurgen et al., 2008).

Several studies have however reported on the deterioration of the settling properties of aerobic granules by overgrowth of filamentous microbial structures, called filamentous bulking. For a review, refer to Liu and Liu (2006). This phenomenon has been observed with volumetric organic loading rates (OLR) above $6 \mathrm{~kg}_{\mathrm{CODs}} \mathrm{d}^{-1} \mathrm{~m}^{-3}$ (Shin et al., 1992; Moy et al., 2002), with highenergy carbon sources such as carbohydrates (Morgenroth et al., 1997; Weber et al., 2007), and at higher mesophilic temperatures of $30-35^{\circ} \mathrm{C}$ (Weber et al., 2007; Ebrahimi et al., 2010). Filamentous overgrowth has been limited with higher up-flow mixing or aeration velocities, and with the use of acetate as carbon source (Liu and Liu, 2006). Despite the reduction of filamentous bulking with this substrate, residual filamentous structures have still been observed, and have been presumed to act as backbones for the immobilization of microbial colonies (Martins et al., 2004). In studies investigating granulation in up-flow anaerobic sludge blanket reactors, it has been observed that the same Methanosaeta-affiliating phylotype was constantly dominating the bacterial community during the evolution of fluffy granules to compact granules under the progressive increase in shear forces in the reactor (Grotenhuis et al., 1992; Hulshoff Pol et al., 2004). In the case of aerobic granules, analysis of bacterial compositions of fluffy and dense granules is required to assess whether different granule structures exhibit the same dominant phylotypes or not.

From the nutrient removal point of view, AGS studies initially concentrated on the formation of aerobic granules, and on the removal of organic matter (Morgenroth et al., 1997; Beun et al., 1999; Tay et al., 2002). Emphasis has then been put on achieving nitrification (Tsuneda et al., 2003), denitrification (Beun et al., 2001; Mosquera-Corral et al., 2005), dephosphatation (Lin et al., 2003), and combined BNR (de Kreuk et al., 2005; Lemaire et al., 2008; Yilmaz et al., 2008) in AGS systems. However, it has been shown that 75-100 days have been required to obtain efficient nutrient removal activities in aerobic granules after reactor start-up with flocculent activated sludge (de Kreuk et al., 2005; Xavier et al., 2007; Ebrahimi et al., 2010; Gonzalez-Gil and Holliger, 2011). In these studies, only carbon has been removed during the start-up period. Some authors have achieved enhanced granulation with faster improvements in nutrient removal performances by seeding reactors with crushed pre-cultivated granules (Pijuan et al., 2011; Verawaty et al., 2012). However, the reason why phosphorus and nitrogen removal activities have been inhibited during the first 3 months of reactor start-up with flocculent inoculation sludge and wash-out conditions has not yet been further investigated. Different microbial ecology studies have mainly been conducted on mature granules (Adav et al., 2010; Gonzalez-Gil and Holliger, 2011), but only little information is available on the microbial composition of early-stage AGS.

The present study aimed to investigate the bacterial community dynamics during the formation of early-stage aerobic granules (0-60 days) in bubble-column SBRs operated under conditions selecting for a fast-settling biomass. The main objective was to assess the effect of wash-out dynamics and operation conditions on the underlying bacterial selection, the shape of aerobic granules, the biomass settling properties, and the nutrient removal performances. We first focused on the differences in predominant bacterial populations between compact and fluffy granules, and on a way to avoid filamentous bulking in AGS systems. We then carried out a detailed monitoring of the start-up of one reactor to detect correlations between operation conditions, bacterial community dynamics and nutrient removal performances. The knowledge gained at the microbial ecology level enabled to determine why nutrient removal deteriorated during the start-up of the granulation process in bubble-column SBRs operated under wash-out conditions.

\section{MATERIALS AND METHODS REACTOR INFRASTRUCTURE AND SEQUENCING BATCH OPERATION}

The design and the operation of the bubble-column SBRs were adapted from de Kreuk et al. (2005). The bubble-columns consisted of internal diameters of $52-62 \mathrm{~mm}$, height-to-diameter ratios of 20-25, and working volumes of 2.1-3.1 L. The SBRs were operated in fixed cycles of $3 \mathrm{~h}$ comprising feeding of the influent wastewater through the settled sludge bed in pulse $(6 \mathrm{~min})$ or anaerobic regime $(60 \mathrm{~min})$, aeration $(110 \mathrm{~min})$, biomass settling (5 min or stepwise decrease from 15 to $3 \mathrm{~min}$ ), and withdrawal of the treated effluent (remaining cycle time). The SBRs were inoculated with $2-3$ gVss $^{-1}$ of flocculent activated sludge originating from full-scale WWTPs. Biomass wash-out conditions were imposed with a short HRT of $6 \mathrm{~h}$ in order to stimulate granulation, according to Beun et al. (1999). A volume exchange ratio of $50 \%$ was applied to this end. The SBRs were operated under biomass dynamic conditions at undefined sludge retention time (SRT). The SRT was a function of the imposed settling time, of the height of the effluent withdrawal point, and of the intrinsic settling properties of the cultivated biomass. The composition of the synthetic cultivation media was similar to the one used by Ebrahimi et al. (2010), and is available in Table A1 in Appendix. Acetate was supplied as sole carbon and energy source at a constant concentration between 400 and $500 \mathrm{mgCODs}_{\mathrm{C}} \mathrm{L}^{-1}$ in the influent wastewater. This resulted in a constant volumetric OLR of $200-250 \mathrm{mg}_{\mathrm{CODs}}$ cycle ${ }^{-1} \mathrm{~L}_{\mathrm{R}}{ }^{-1}$ (or $1.6-2.0 \mathrm{~kg}_{\mathrm{CODs}} \mathrm{d}^{-1} \mathrm{~m}_{\mathrm{R}}{ }^{-3}$ daily equivalents), and in an initial biomass specific OLR of 50-60 mg CODs $_{\text {cycle }}{ }^{-1}$ gCODx $^{-1}$ (or 0.4-0.6 $\mathrm{kg}_{\mathrm{CODs}} \mathrm{d}^{-1} \mathrm{~kg}_{\mathrm{CODx}}{ }^{-1}$ daily equivalents). The biomass specific OLR was a dynamic function of the residual biomass concentration evolving in the reactor. The phosphorous and nitrogenous nutrient ratios amounted to $4.8 \mathrm{~g}_{\mathrm{P}-\mathrm{PO} 4}$ and $12.5 \mathrm{~g}_{\mathrm{N}-\mathrm{NH} 4}$ per $100 \mathrm{~g}_{\mathrm{CODs}}$, respectively. During aeration, air was supplied at the target flow-rate with mass flow controllers (Brooks Instrument, Netherlands), DO was not controlled and reached saturation $\left(8-9 \mathrm{mg}_{\mathrm{O} 2} \mathrm{~L}^{-1}\right)$, and $\mathrm{pH}$ was regulated at $7.0 \pm 0.2$ by addition of $1 \mathrm{M} \mathrm{HCl}$ or $\mathrm{NaOH}$ with a proportional-integral controller.

\section{GRANULATION EXPERIMENTS}

In the first part, the granulation process was studied in five reactors (R1-R5) where the bacterial community compositions of early-stage AGS were analyzed in relation with the different combinations of operation parameters, as summarized in Table $\mathbf{1}$.

The first two reactors R1 and R2 were inoculated with a flocculent activated sludge originating from a WWTP designed for 
Table 1 | Operation parameters applied during the granulation start-up experiments.

\begin{tabular}{|c|c|c|c|c|c|}
\hline Reactor $^{1}$ & $\begin{array}{l}\text { Inoculation } \\
\text { sludge }^{2}\end{array}$ & $\begin{array}{l}\text { Temperature } \\
\left({ }^{\circ} \mathrm{C}\right)\end{array}$ & $\begin{array}{l}\text { Feeding } \\
\text { regime }\end{array}$ & $\begin{array}{l}\text { Up-flow } \\
\text { SAV } \\
\left(\mathrm{cm} \mathrm{s}^{-1}\right)\end{array}$ & $\begin{array}{l}\text { Settling } \\
\text { time }^{6} \\
\text { (min) }\end{array}$ \\
\hline R1 & OMR & $23 \pm 2^{3}$ & Pulse & $1.8 / 4.0^{5}$ & 5 \\
\hline R2 & OMR & $23 \pm 2^{3}$ & Anaerobic & $1.8 / 4.0^{5}$ & 5 \\
\hline R3 & BNR & 20 & Anaerobic & 1.8 & 15 to 3 \\
\hline R4 & BNR & 20 & Anaerobic & 2.0 & 15 to 3 \\
\hline R5 & BNR & 30 & Anaerobic & 1.8 & 15 to 3 \\
\hline R6 & BNR & $23 \pm 2^{3}$ & Anaerobic & 2.5 & 15 to 3 \\
\hline
\end{tabular}

${ }^{1} R 1-R 5$ were run in the first part of the study investigating differences in bacterial community compositions of early-stage aerobic granules. R6 was operated for detailed analysis of process conditions governing bacterial selection during granulation.

${ }^{2}$ The reactors were inoculated with flocculent activated sludge originating either from a WWTP designed for organic matter removal (OMR) only, or from a WWTP operated for full biological nutrient removal (BNR).

${ }^{3} R 1, R 2$, and $R 6$ were operated at ambient temperature without temperature control.

${ }^{4}$ The synthetic influent wastewater was supplied either in 6 min with a pulsefeeding regime, or in $60 \mathrm{~min}$ with an anaerobic-feeding plug-flow regime.

${ }^{5} R 1$ and $R 2$ were operated first with a low up-flow superficial air velocity (SAV) of $1.8 \mathrm{~cm} \mathrm{~s}^{-1}$. This parameter was doubled after 4 weeks for remediating filamentous overgrowth.

${ }^{6}$ Two different biomass settling patterns were tested with a constant settling time of $5 \mathrm{~min}$, or with stepwise decrease in the settling time from 15 to $3 \mathrm{~min}$.

organic matter removal (OMR) only (ERM Morges, Switzerland). R1 and R2 were operated during at most 50 days at ambient temperature $\left(23 \pm 2^{\circ} \mathrm{C}\right)$, with pulse $(6 \mathrm{~min})$ or anaerobic plugflow (60 $\mathrm{min}$ ) feeding regimes, with an initially low up-flow SAV of $1.8 \mathrm{~cm} \mathrm{~s}^{-1}$ during aeration, and with a constant settling time of $5 \mathrm{~min}$. After having observed proliferation of fluffy granules (30 days), the up-flow SAV was increased to $4.0 \mathrm{~cm} \mathrm{~s}^{-1}$ in order to obtain dense granules.

The reactors R3, R4, and R5 were inoculated with a flocculent activated sludge originating for a WWTP designed for full BNR along an anaerobic-anoxic-aerobic process (ARA Thunersee, Switzerland). These reactors were operated at either low $\left(20^{\circ} \mathrm{C}\right.$, $\mathrm{R} 3$ and $\mathrm{R} 4)$ or high $\left(30^{\circ} \mathrm{C}, \mathrm{R} 5\right)$ mesophilic temperature, with anaerobic plug-flow feeding $(60 \mathrm{~min})$, with a low up-flow SAV of $1.8-2.0 \mathrm{~cm} \mathrm{~s}^{-1}$ during aeration, and with a stepwise decrease in the settling time from 15 to $3 \mathrm{~min}$ in $10-15$ days. The operation of R4 and R5 has previously been described in detail by Ebrahimi et al. (2010), and lasted over 40 days. R3 was run on a shorter period of 15 days, but microbial ecology data were collected at higher frequency during the transition from flocculent to granular sludge.

In the second part, reactor R6 was operated with a combination of conditions selecting for the formation of dense fast-settling granules and a detailed monitoring of operation conditions, bacterial community compositions, and nutrient removal performances was carried out. R6 was inoculated with flocculent activated sludge taken from the BNR-WWTP, and was operated during 60 days at $23 \pm 2{ }^{\circ} \mathrm{C}$ and $\mathrm{pH} 7.0 \pm 0.2$, with anaerobic plug-flow feeding (60 $\mathrm{min}$ ), a moderate up-flow SAV of $2.5 \mathrm{~cm} \mathrm{~s}^{-1}$, and a stepwise decrease in the settling time from 15 to $3 \mathrm{~min}$. Temperature, $\mathrm{pH}$, DO, and electrical conductivity signals were collected on-line. Concentrations of biomass present in the reactor and in the treated effluent, and microbial ecology data were collected on a daily basis. Liquid phase samples were taken every 3-5 days for physicochemical analyses of soluble compounds in the influent wastewater, in the reactor at the end of the anaerobic phase, and in the treated effluent.

\section{CHARACTERIZATION OF METABOLIC ACTIVITIES OF THE INOCULATION SLUDGE TAKEN FROM THE BNR-WWTP}

The nutrient removal capacities of the inoculation sludge taken from the BNR-WWTP were tested in anaerobic, aerobic, and anoxic batch tests, and compared to the operation data of the BNR-WWTP. The tests were run at $20^{\circ} \mathrm{C}$ in $2-\mathrm{L}$ stirred tank reactors with a biomass concentration of $3-4 \mathrm{gVSS} \mathrm{L}^{-1}$ and with similar starting nutrient concentrations as in R6.

\section{ANALYSES OF SOLUBLE COMPOUNDS AND BIOMASS}

Acetate concentration was determined with a high performance liquid chromatograph equipped with an organic acids ion exclusion column ORH-801 (Transgenomics, UK) and a refraction index detector (HPLC Jasco Co-2060 Plus, Omnilab, Germany). The concentration of anions was measured with an ICS-90 ion exchange chromatograph equipped with an IonPacAS14A column and an electrical conductivity detector (Dionex, Switzerland). The concentration of cations was measured with an ICS-3000A ion exchange chromatograph equipped with an IonPacCS16 column and an electrical conductivity detector (Dionex, Switzerland).

The particulate concentrations of total (TSS), volatile (VSS), and inorganic suspended solids (ISS) were measured according to de Kreuk et al. (2005). Granules were observed by light microscopy.

\section{MOLECULAR ANALYSES OF BACTERIAL COMMUNITY COMPOSITIONS}

The compositions and dynamics of the bacterial communities were characterized by terminal-restriction fragment length polymorphism (T-RFLP) analysis targeting the v1-v3 hypervariable region of the Eubacteria 16S rRNA gene pool. The T-RFLP method was adapted from Rossi et al. (2009) and Ebrahimi et al. (2010), and contained the following modifications. DNA was extracted from $100 \mathrm{mg}$ of homogenized biomass samples using the Maxwell 16 Tissue DNA Purification System (Promega, Switzerland). Gene fragments of $500 \mathrm{bp}$ were amplified by PCR using universal eubacterial primers: a FAM-labeled 8-F forward primer (FAM-5'-GAGTTTGATCMTGGCTCAG- $3^{\prime}$ ) and an unlabeled 518-R reversed primer ( $5^{\prime}$-ATTACCGCGGCTGCTGG-3'). The PCR program was run in a T3000 Thermocycler (Biometra $\mathrm{GmbH}$, Germany) in 30 cycles comprising a longer denaturation time than the one used by the authors, for optimal amplification of Accumulibacter-related polyphosphate-accumulating organisms (PAO): $10 \mathrm{~min}$ initial denaturation $\left(95^{\circ} \mathrm{C}\right), 1 \mathrm{~min}$ denaturation $\left(95^{\circ} \mathrm{C}\right), 45 \mathrm{~s}$ primer annealing $\left(56^{\circ} \mathrm{C}\right), 2 \mathrm{~min}$ elongation $\left(72^{\circ} \mathrm{C}\right)$, $10 \mathrm{~min}$ final elongation $\left(72^{\circ} \mathrm{C}\right)$. The amplicons were purified and concentrated using Invisorb MSB Spin PCRapace purification kits (Invitek Stratec Molecular GmbH, Germany). Amounts of $200 \mathrm{ng}$ 
of purified PCR products were digested at $37^{\circ} \mathrm{C}$ for $3 \mathrm{~h}$ with 0.5 units of the HaeIII endonuclease (Promega, Switzerland). Volumes of $1 \mu \mathrm{L}$ of digestion products were mixed with $8.5 \mu \mathrm{L}$ of HiDi formamid and $0.5 \mu \mathrm{L}$ of GeneScan 600-LIZ internal size standard (Applied Biosystems, USA), and were denaturated for 2 min at $95^{\circ} \mathrm{C}$. The terminal-restriction fragments (T-RFs) were separated and analyzed by capillary gel electrophoresis in an ABI Prism 3100-Avant Genetic Analyzer using a fluid POP-6 gel matrix and fluorescence laser detection (Applied Biosystems, USA). The T-RFLP profiles were aligned using the Treeflap crosstab macro (Rees et al., 2004). The bacterial community structures were expressed as relative contributions of all operational taxonomic units (OTU) contributing to the total measured fluorescence. Predominant OTUs with relative abundances above $2 \%$ were presented in stacked bar plots for simplified visual observation. Three single biomass samples from the whole set of samples of the study were analyzed in triplicates to determine the overall relative standard deviation related to the T-RFLP method (6\%). For reactor R6, biomass equivalents of target OTUs were expressed by multiplying their relative abundances by the mass of VSS present in the reactor.

\section{ANALYSIS OF THE RICHNESS AND DIVERSITY OF THE BACTERIAL COMMUNITY EVOLVING IN REACTOR R6}

Richness and Shannon's H' diversity indices were computed with the $\mathrm{R}$ software version 2.14.1 equipped with the Vegan package (R-Development-Core-Team, 2008; Oksanen et al., 2009) based on the full T-RFLP profiles collected during experiment R6. Mathematical geometric evolution models were fitted to the measured richness and diversity profiles with the Berkeley Madonna software (Macey et al., 2000) in order to simulate the evolution of both indices in the reactor. Standard deviation intervals on model predictions were computed from 1000 Monte Carlo simulations on underlying parameters.

\section{PHYLOGENETIC AFFILIATION OF OPERATIONAL TAXONOMIC UNITS}

Predominant OTUs detected in R1-R5 were affiliated to closest bacterial relatives by using the cloning-sequencing databank developed by Ebrahimi et al. (2010) and complemented in the present study. Two DNA extracts from biomass samples collected in R6 at day 2 (flocculent sludge) and day 59 (granular sludge) were sent to Research and Testing Laboratory (Lubbock, TX, USA) for 454 Tag-encoded FLX amplicon pyrosequencing with a Genome Sequencing FLX System (Roche, Switzerland) using the procedure developed by Sun et al. (2011), and the same primers (8-F and 518-R) as the ones used for T-RFLP analysis. The pyrosequencing datasets were denoised and processed with the PyroTRF-ID bioinformatics procedure developed by Weissbrodt and Shani, et al. (paper submitted), which includes sequence annotation with the Greengenes database (McDonald et al., 2012), digital T-RFLP profiling, comparison of digital and experimental T-RFLP profiles, and phylogenetic affiliation of OTUs. QIIME algorithms were used in the denoising process (Caporaso et al., 2010).

\section{BACTERIOME ANALYSIS}

The pyrosequencing datasets of the two biomass samples collected in R6 were analyzed by the metagenomics RAST server
(MG-RAST; Meyer et al., 2008) for annotation and comparative analysis. The Ribosomal Database Project (RDP; Cole et al., 2009) was used as sequence annotation source. A minimum identity cutoff of $97 \%$ was applied in order to retain only the closest bacterial affiliations. A circular phylogenetic tree was constructed with the pyrosequencing datasets of the two samples. The tree was complemented with two bar plots representing the relative abundances of the bacterial genera in both samples. Richness and Shannon's H' diversity indices were also computed from these datasets.

\section{RESULTS \\ COMPOSITION AND ACTIVITY OF EARLY-STAGE GRANULES CULTIVATED FROM FLOCCULENT OMR-SLUDGE}

Reactors R1 and R2 were inoculated with flocculent activated sludge taken from an aeration tank of a WWTP designed for OMR only (OMR-sludge). Operation at ambient temperature $\left(23 \pm 2^{\circ} \mathrm{C}\right)$, with acetate as carbon source, a low up-flow SAV of $1.8 \mathrm{~cm} \mathrm{~s}^{-1}$, and a fixed settling time of $5 \mathrm{~min}$ resulted in the proliferation of slow-settling fluffy early-stage granules (Figure 1A). Segmented chain filamentous bacterial structures were detected by light microscopy (Figure 1B). The underlying bacterial community compositions are presented in Figure 2A. Closest bacterial affiliations of specific OTUs detected in these reactors are given in Table A2 in Appendix. The fluffy granules obtained in R1 with pulse feeding $(6 \mathrm{~min})$ were predominantly composed of Burkholderiales affiliates related to the Sphaerotilus-Leptothrix group (OTU-208, 23-33\%), and by Zoogloea spp. belonging to Rhodocyclales (OTU-195, 12-27\%). In R2 operated with anaerobic feeding (60 min), Sphaerotilus-Leptothrix affiliates dominated (39-50\%) over Zoogloea spp. (2-8\%) in fluffy granules.

The application of a higher up-flow SAV of $4.0 \mathrm{~cm} \mathrm{~s}^{-1}$ after 30 days resulted in the recovery of smooth and dense fast-settling granules. The predominant organisms shifted from SphaerotilusLeptothrix affiliates to Zoogloea spp. In the granules of R1, Zoogloea spp. (27\%) and Thaurea spp. (OTU-217,30\%) outcompeted Burkholderiales $(<1 \%)$. The dense granules of R2 were highly dominated by Zoogloea spp. (47-57\%). Burkholderiales decreased to $2 \%$ after day 48 . OTU-185 affiliating with Gammaproteobacteria and with Rhizobiales from Alphaproteobacteria was present up to $17 \%$.

At physical reactor boundaries, filamentous bulking led to deteriorated sludge settling. Both reactors displayed poor nutrient removal performances. After the recovery of fast-settling granules, nutrient removal did not improve. After pulse feeding in $\mathrm{R} 1$, acetate was fully removed within $40 \mathrm{~min}$ during the aeration phase. In R2 where slow plug-flow anaerobic feeding was applied, more than $90 \%$ of the acetate leaked into the aeration phase during which it was fully consumed. Ammonium was not nitrified and biological dephosphatation did not occur. Only partial nitrogen $(20 \%)$ and phosphorus removal (10\%) was detected in both reactors which was probably due to anabolic requirements.

\section{COMPOSITION AND ACTIVITIES OF EARLY-STAGE GRANULES CULTIVATED FROM FLOCCULENT BNR-SLUDGE}

The reactors R3, R4, and R5 were operated with an inoculation sludge originating from a WWTP designed for full BNR, under 

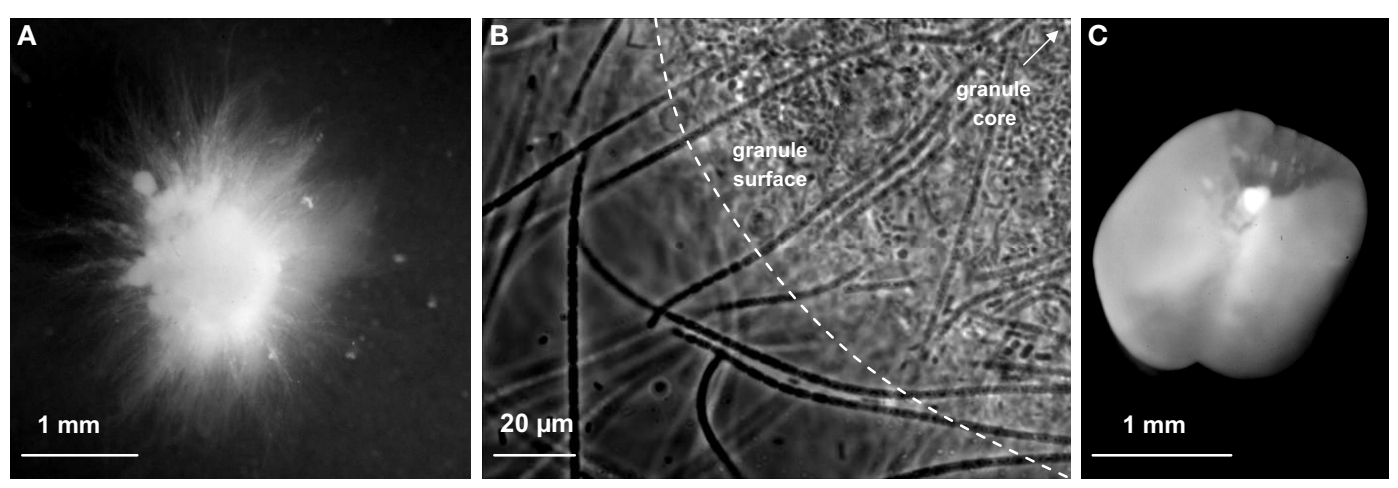

FIGURE 1 | Example of early-stage aerobic granule structures observed with light microscopy. Fluffy slow-settling granule obtained after 30 days in reactor R2 with OMR-sludge and low up-flow SAV of $1.8 \mathrm{~cm} \mathrm{~s}^{-1}$, and exhibiting filamentous outer structures (A). Filamentous segmented chain bacterial structures interspersing across the granular biofilm observed on a sample collected on day 22 in R2 (B). Dense fast-settling granule present after 50 days in R6 with BNR-sludge and moderate up-flow SA of $0.025 \mathrm{~m} \mathrm{~s}^{-1}$, and displaying a tulip-like folded structure around a more opaque internal core (C).

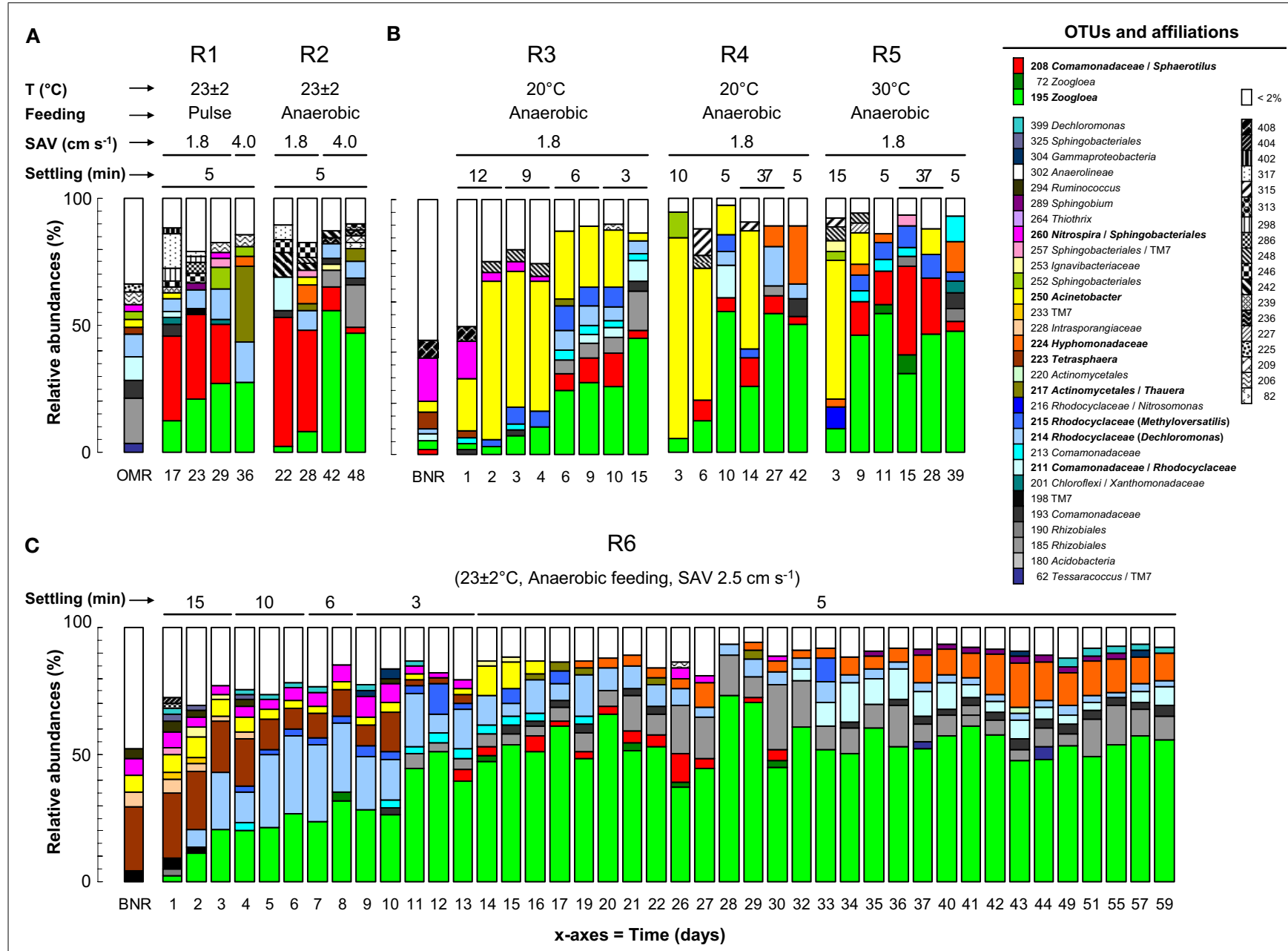

FIGURE 2 | Dynamics of predominant bacterial OTUs analyzed with T-RFLP during the six granulation experiments. Reactors $R 1$ and $R 2$ were inoculated with activated sludge from the OMR-WWTP (A). R3, R4, and R5 were inoculated with activated sludge from the BNR-WWTP (B). High resolution bacterial ecology data were collected from $\mathrm{R} 6$ to assess the effect of wash-out dynamics on bacterial selection during granulation (C). Main operation conditions are indicated at the top of each graph. Closest bacterial affiliations of target OTUs presented in Table $\mathbf{2}$ are given on the right. 
anaerobic feeding, and with a stepwise decrease in the settling time from $15-3 \mathrm{~min}$. The three reactors resulted in the formation of smooth and dense fast-settling granules after 9-10 days (Figure 1C). The underlying bacterial community dynamics are presented in Figure $\mathbf{2 B}$. The inoculation sludge from the BNR-WWTP was dominated by Nitrospira and Sphingobacteriales (OTU-260, 17\%), Tetrasphaera spp. (OTU-223, 7\%), and an unidentified OTU-408 (7\%). Zoogloea spp. (OTU-195), Burkholderiales (OTU-207), OTU-210 affiliating with Acidobacteriales and Firmicutes, and OTU-214 affiliating with Rhodocyclalesrelated organisms such as Dechloromonas and Methyloversatilis spp. were present in lower abundances (2-3\%). In all three reactors, the sludge was still in the flocculent state over the first 6 days. The predominant organisms of the inoculum were replaced within 2-3 days by Acinetobacter spp. (OTU-250, 21-79\%). Granulation correlated with the proliferation of Zoogloea spp. (28-55\%). Dechloromonas (5-16\%), Methyloversatilis (3-10\%), and Rhizobiales (4-16\%) were detected as flanking populations. Hyphomonadaceae affiliates were abundantly present after 42 days in R4 (23\%), and after 39 days in R5 (12\%). In contrast to the operation at $20^{\circ} \mathrm{C}$ in $\mathrm{R} 3$ and $\mathrm{R} 4$ where dense fast-settling granules were constantly present, the operation at $30^{\circ} \mathrm{C}$ in $\mathrm{R} 5$ led to the proliferation of organisms affiliated to the Sphaerotilus-Leptothrix group $(35 \%)$ and resulted in a mixture of dense and fluffy granules. Even though a BNR-sludge was used as inoculum, nitrification and dephosphatation activities were not detected in the three AGS systems. Acetate was only consumed to a small extent during the anaerobic feeding phases (18-25\%) and fully removed during the aeration phases.

\section{DYNAMICS OF BACTERIAL COMMUNITIES AND PROCESS PERFORMANCE UNDER WASH-OUT CONDITIONS}

For reactor R6, high frequency of data collection allowed to detect correlations between operation conditions, bacterial dynamics, and BNR performances during early-stage granulation under wash-out conditions. Changes in biomass properties are presented in Figures 3A,B in function of the settling time. With initial settling times of 15 and then $10 \mathrm{~min}$ during the first 5 days, the activated sludge remained in the flocculent state and a biomass concentration of 2.45-2.95 gVss $\mathrm{L}^{-1}$ was maintained in the reactor, forming a settled sludge blanket of $15-30 \mathrm{~cm}$, and the SRT amounted to 12 days. The decrease in the settling time from 6 to $3 \mathrm{~min}$ at day 8 resulted in extensive biomass wash-out (Figure 3C). An extremely low residual biomass concentration of $0.2 \mathrm{gvss}^{-1}$ was remaining in the system, and formed a settled sludge blanket of only $1 \mathrm{~cm}$. The SRT dropped to 0.5 day, and approached the HRT of 0.25 day. First granule nuclei were observed after 10 days. At day 12, the settling time was increased to $5 \mathrm{~min}$ as safety measure to keep the granules in the system. The granular biomass increased to $4.0 \mathrm{gVSS}_{\mathrm{VS}} \mathrm{L}^{-1}$ at day 37 , progressively stabilized at $5.3 \pm 0.4 \mathrm{gVss} \mathrm{L}^{-1}$ after 52 days, and formed a settled sludge blanket of $32-40 \mathrm{~cm}$. The fraction of ISS amounted to $38 \%$ in the inoculation sludge, and to $12 \%$ in the early-stage AGS. An example of a dense fast-settling granule present in R6 after 50 days is presented in Figure 1C.

The reactor was operated with a constant volumetric OLR of $250 \mathrm{mgCODs}_{\text {cycle }}{ }^{-1} \mathrm{~L}_{\mathrm{R}}{ }^{-1}$. The biomass specific OLR however evolved with the residual biomass concentration from initially 51 to $685 \mathrm{mg}_{\mathrm{CODs}} \mathrm{cycle}^{-1} \mathrm{~g}_{\mathrm{CODx}}{ }^{-1}$ between day 8 and day 20 after the intensive biomass wash-out (Figure 3D). As the AGS biomass grew in the system, the biomass specific OLR progressively decreased to $20 \mathrm{mg}_{\mathrm{CODs}} \mathrm{cycle}^{-1} \mathrm{~g}_{\mathrm{CODx}}{ }^{-1}$.

Tetrasphaera spp. (OTU-223) dominated in the inoculation sludge $(26 \%)$, and were progressively replaced in the flocculent sludge after 5 days by Zoogloea spp. (OTU-195, 21\%) and by OTU-214 (29\%; Figure 2C). During this initial phase, mainly Dechloromonas and Comamonadaceae relatives contributed to OTU-214, whereas Accumulibacter accounted for only $1 \%$ of this OTU (Table 2). When expressed as biomass concentration equivalents, OTU-195 and OTU-214 increased during this period up to 0.6 and $0.8 \mathrm{~g}_{\mathrm{VSS}} \mathrm{L}^{-1}$, respectively (Figure $3 \mathrm{E}$ ). The extensive biomass wash-out at day 8 resulted in the rapid decrease in the masses of all bacterial populations below $0.1 \mathrm{gVSS}_{\mathrm{V}} \mathrm{L}^{-1}$. Zoogloea spp. then rapidly proliferated up to a relative abundance of $54 \pm 8 \%$ in the early-stage AGS from day 15 to day 60 . Other Rhodocyclales affiliates (OTUs 214 and 215) declined below 5\% at day 26. The concentration of Zoogloea spp. amounted to $3.0 \mathrm{gVSS} \mathrm{L}^{-1}$ after 52 days. The concentration of other Rhodocyclales affiliates remained low, but exhibited a slight increase from 0.06 to $0.19 \mathrm{gVsS} \mathrm{L}^{-1}$ from day 10 to day 60 .

After granulation, additional bacterial populations evolved in the AGS. The relative abundance of Rhizobiales (OTU-185) increased from $6 \%$ at day 11 to $26 \%$ at day 39 , and stabilized subsequently at $10 \pm 4 \%$ over the next 20 days. Hyphomonadaceae (OTU-224) were detected above $1 \%$ from day 17 on, and were present at $13 \pm 3 \%$ after day 37. Comamonadaceae (OTU-211) increased up to $16 \%$ at day 34 , and remained at $5 \pm 2 \%$ until the end of the experiment. Acinetobacter spp. (OTU-250) were only detected during the first 17 days in relative abundances of 3-12\%. OTU-260 affiliating with Sphingobacteriales (and Nitrospira probably to a less extent) was present up to $7 \%$ at day 10 , but was only present at low relative abundances of $<1-4 \%$ in the early-stage granules. Nitrifiers were not detected above the detection limit of the T-RFLP method.

Wastewater treatment plants operation data and metabolic batch tests indicated that the inoculation sludge was efficiently removing organic matter (95\%), nitrogen $(97 \%)$, and phosphorus (92\%). BNR activities were detected in R6 during initial operation with a high settling time (Figures 4A,B). After 6 days, $48 \%$ of the acetate load was consumed during anaerobic feeding, ammonium was efficiently nitrified to nitrate (97\%), and $40 \%$ of nitrogen was removed. Two millimoles of orthophosphate were cycled in alternating anaerobic-aerobic conditions (Figure 4C), but only $9 \%$ of phosphorus was effectively removed. After intensive biomass wash-out at day 8, BNR activities were lost except carbon removal. Between day 10 and day 40, less than $4 \%$ of acetate was taken up during the anaerobic feeding phase, and only $31 \pm 6 \%$ of ammonium was removed, presumably by assimilation into biomass. The orthophosphate cycling activity was lost, and phosphorus removal remained at $11 \pm 4 \%$ until the end of the experiment. After day 40 , ammonium and nitrogen removal recovered to 77 and $60 \%$, respectively. However, nitrite instead of nitrate accumulated in the system. A slight increase in the anaerobic acetate uptake (up to $22 \%)$ was detected. 


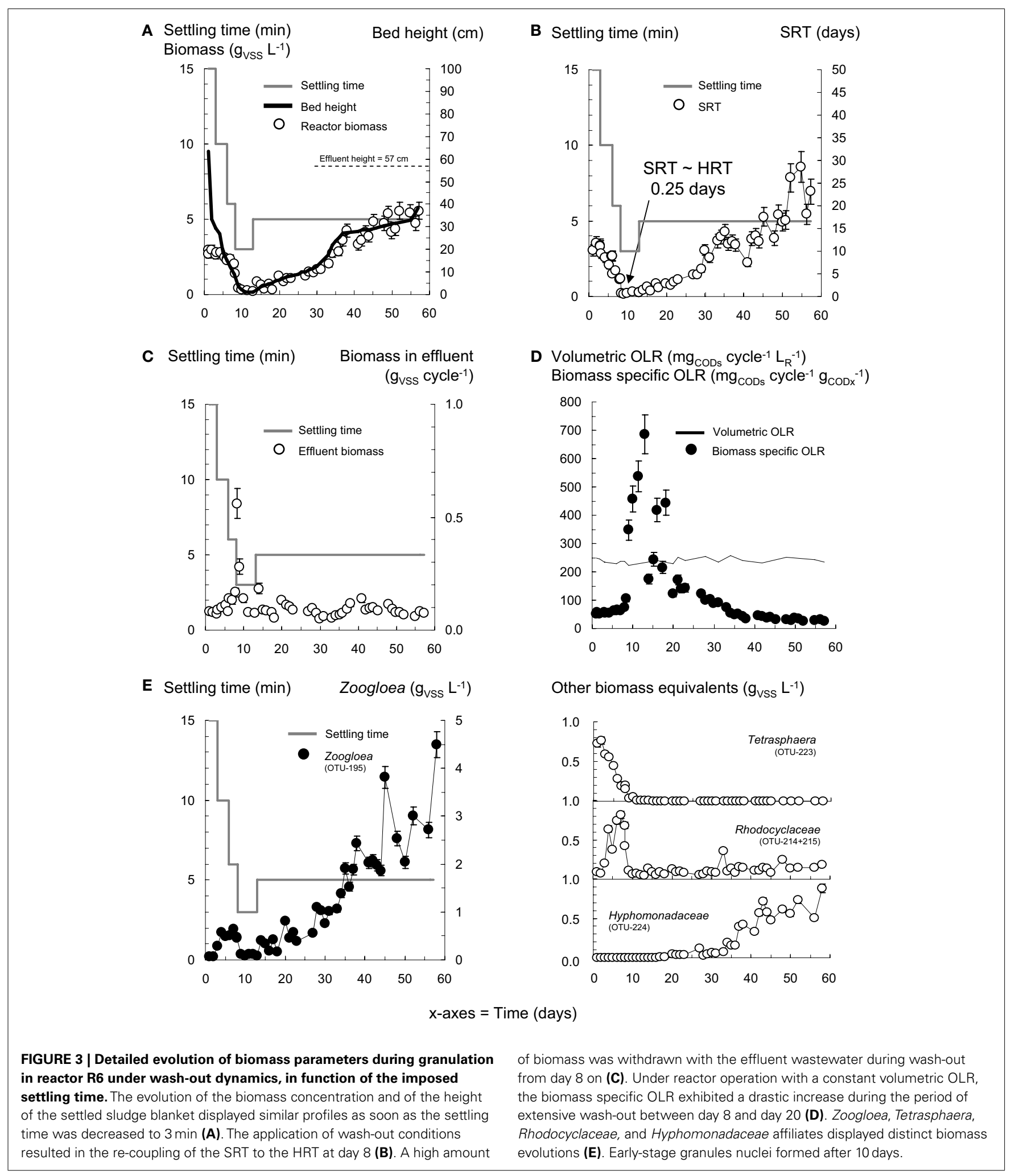

\section{BACTERIOME ANALYSIS OF THE FLOCCULENT AND GRANULAR SLUDGE IN R6}

Based on the T-RFLP data collected from R6, the bacterial community was displaying a strong decrease of $66 \%$ in richness and
$52 \%$ in diversity during the start-up of the reactor (Figure 5). The bacterial community of the activated sludge taken from the full-scale BNR was associated with a richness of 53 OTUs and a diversity index of 3.3. The bacterial community of the early-stage 


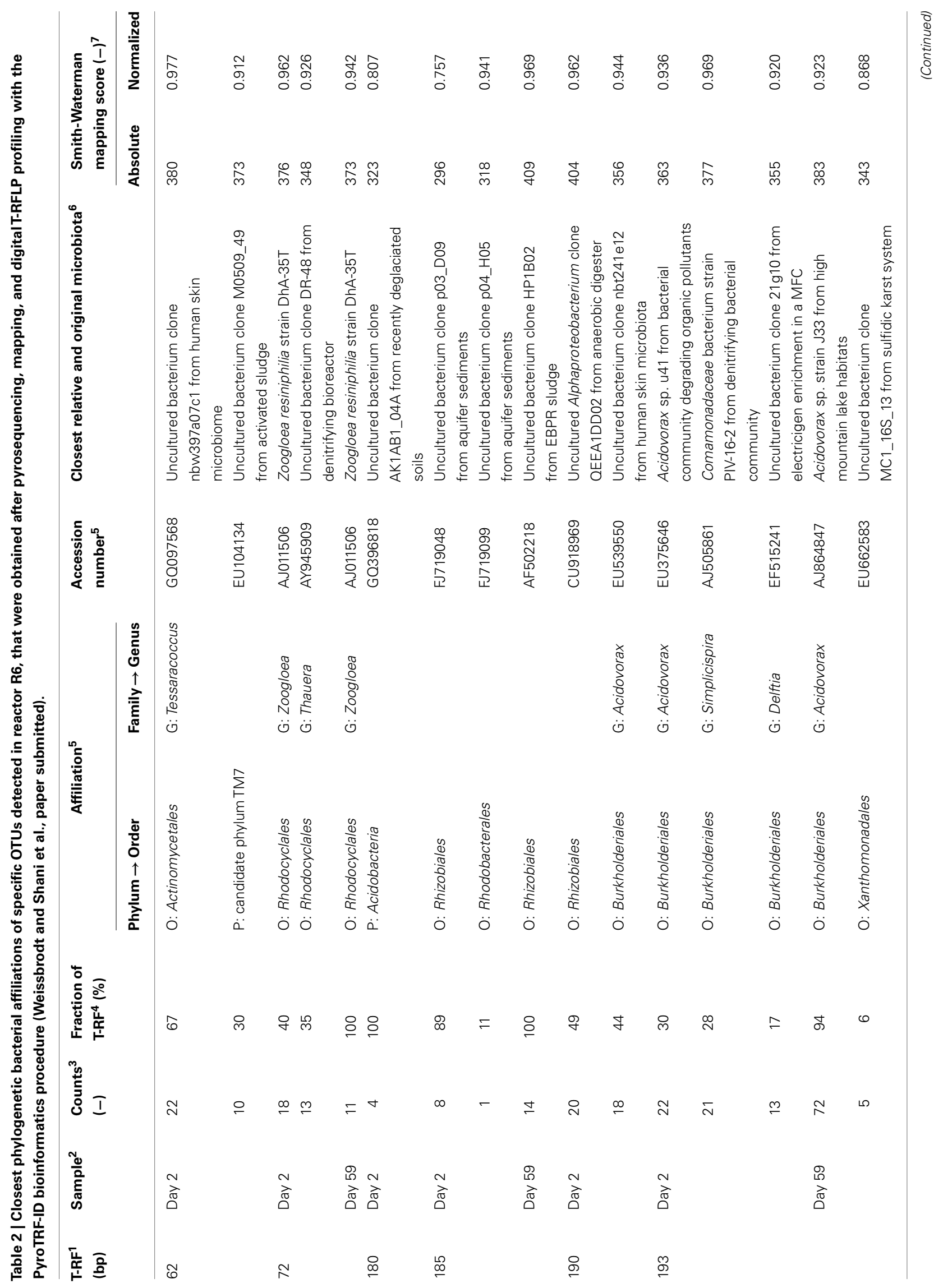




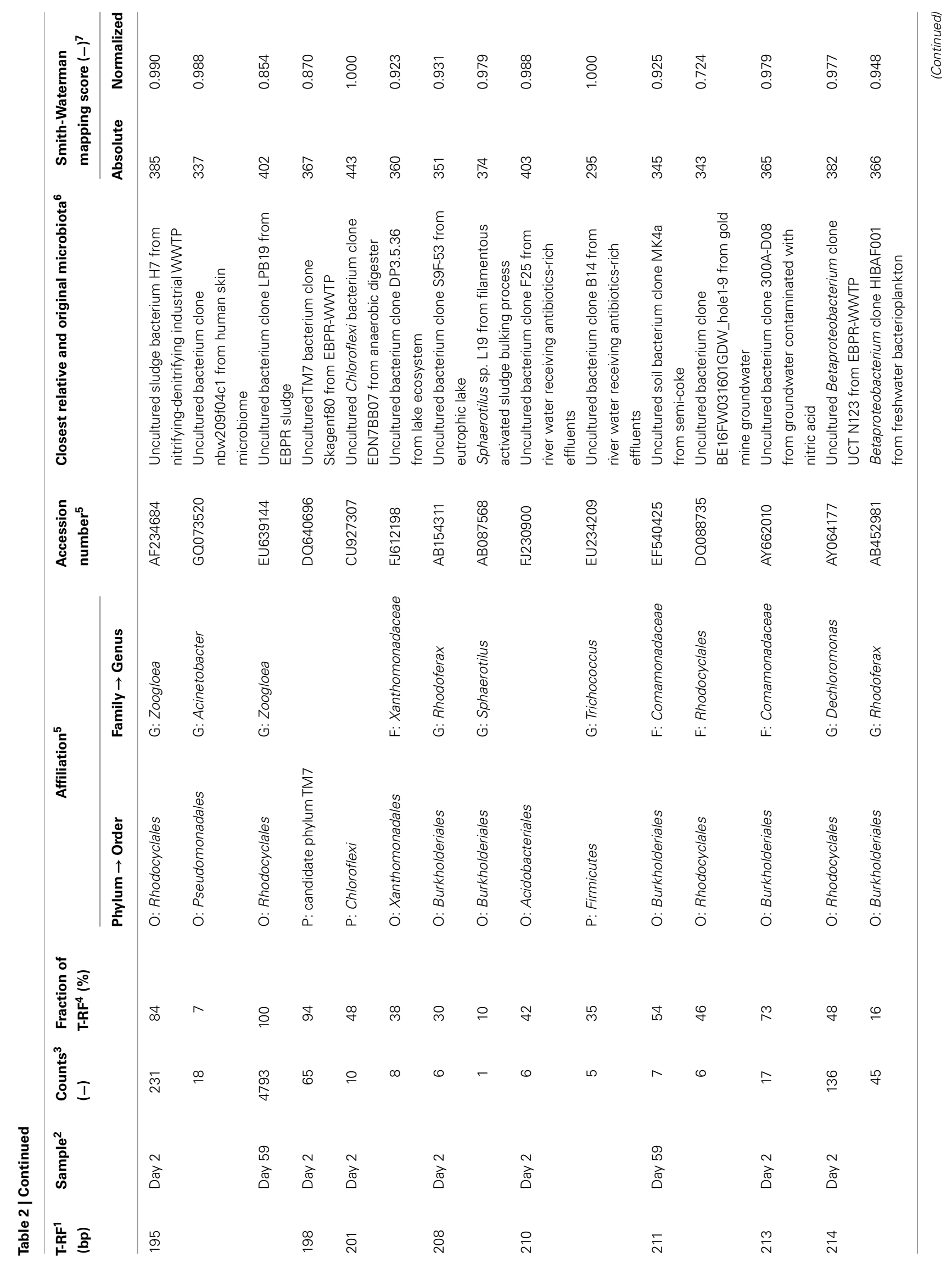




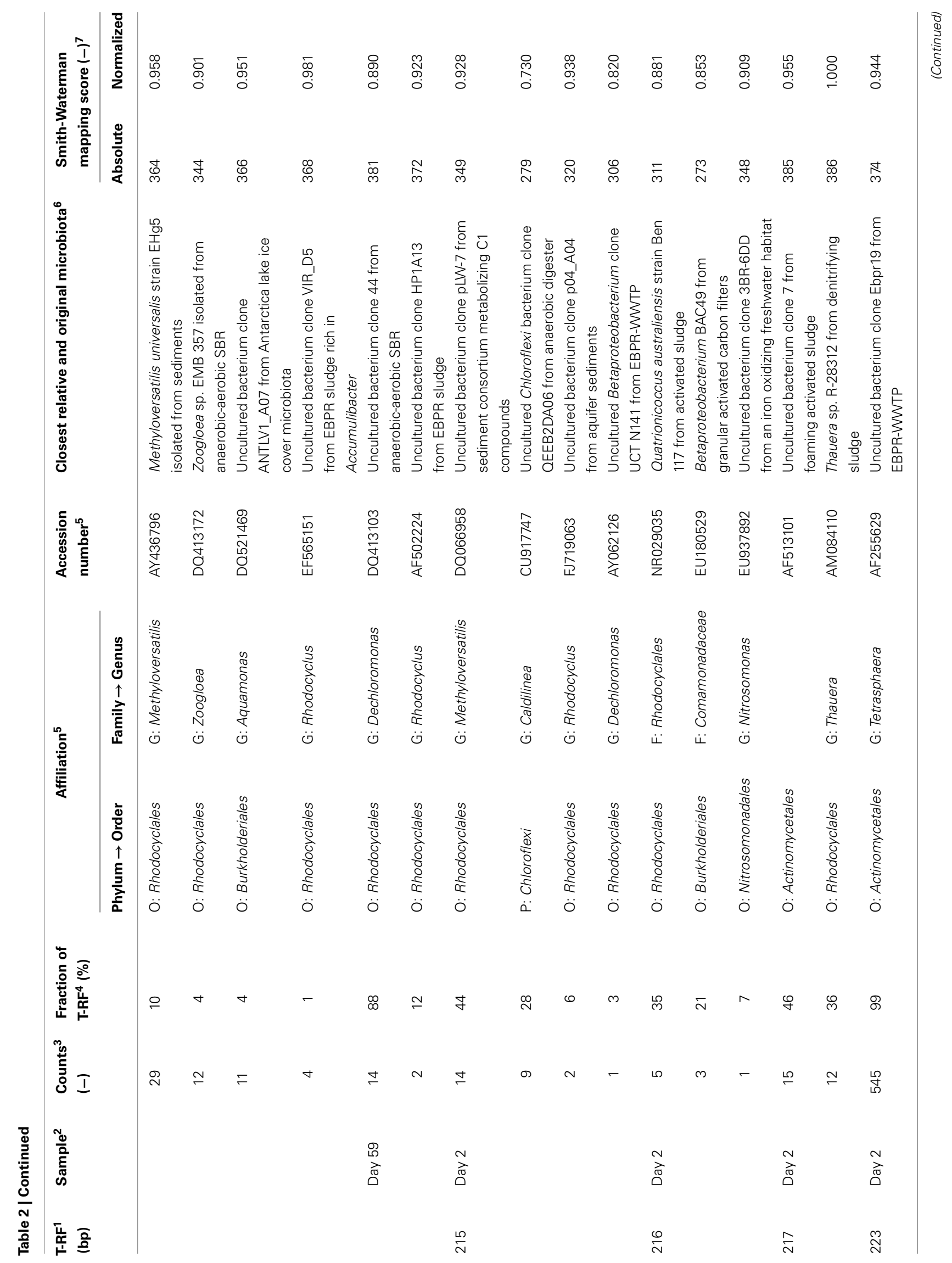




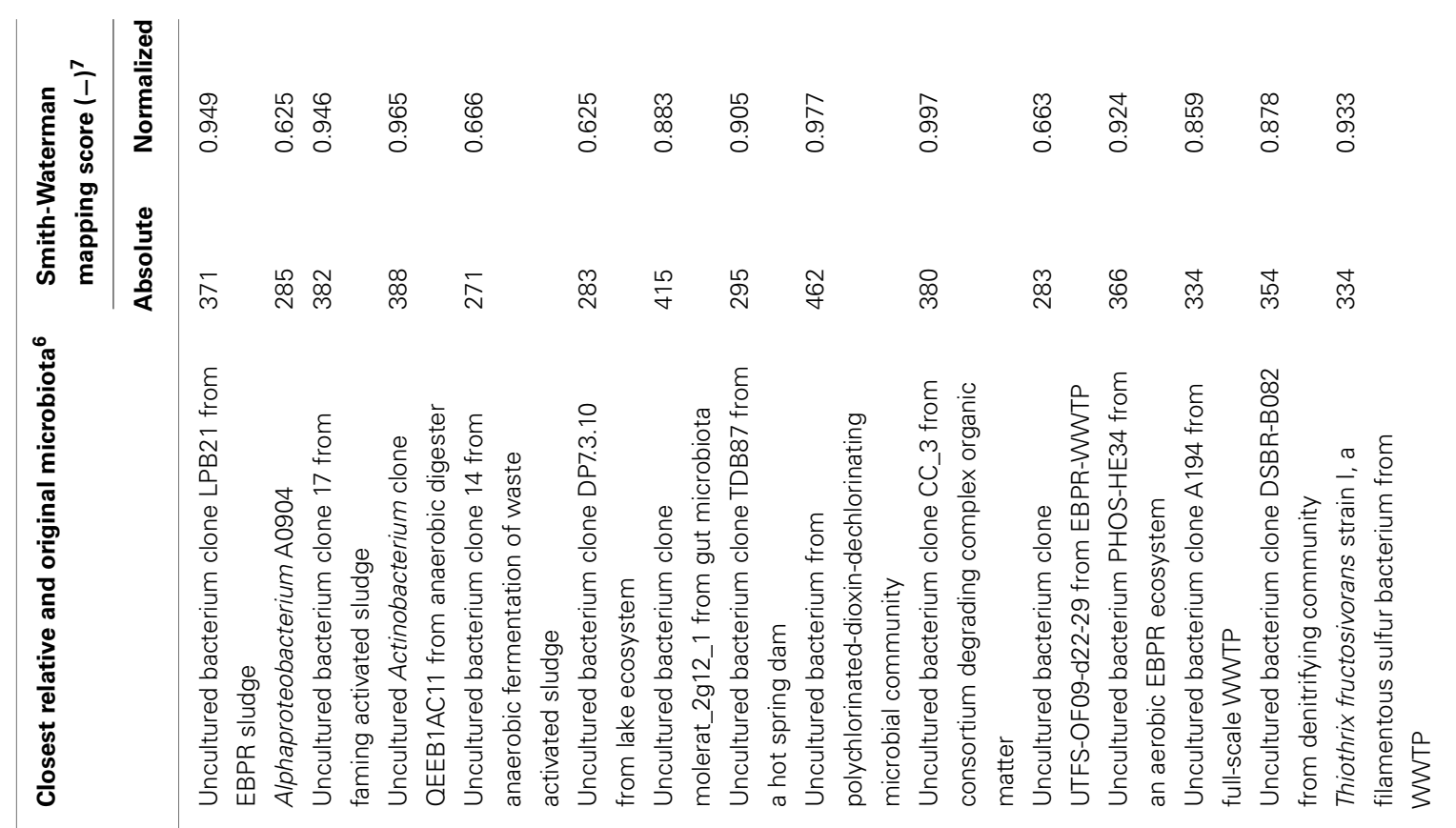

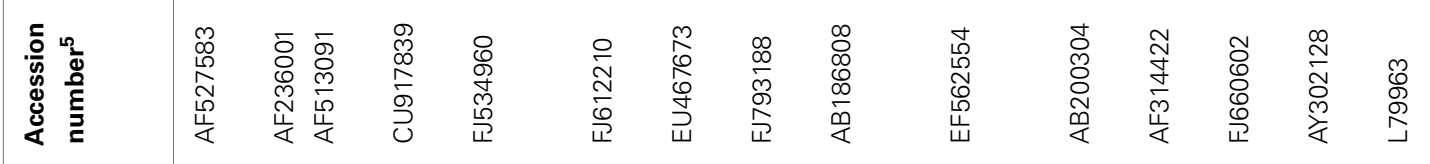
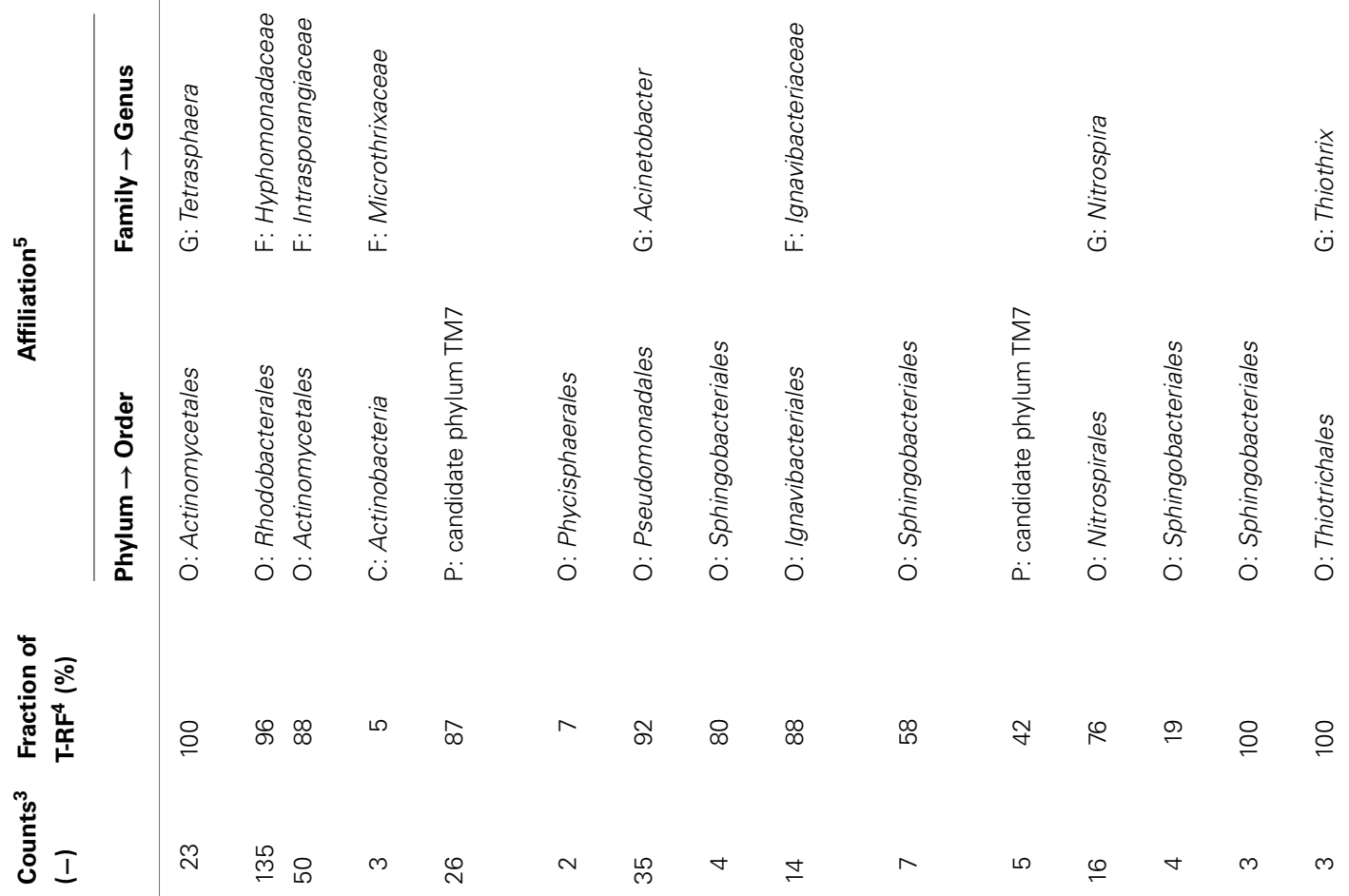

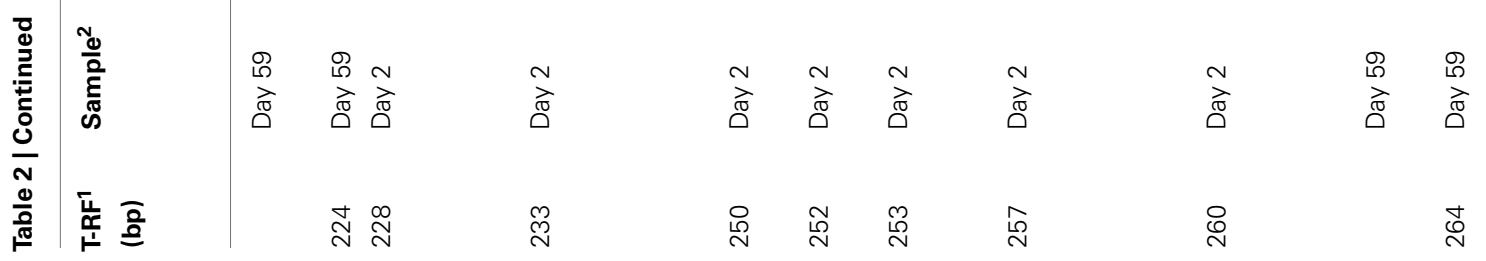




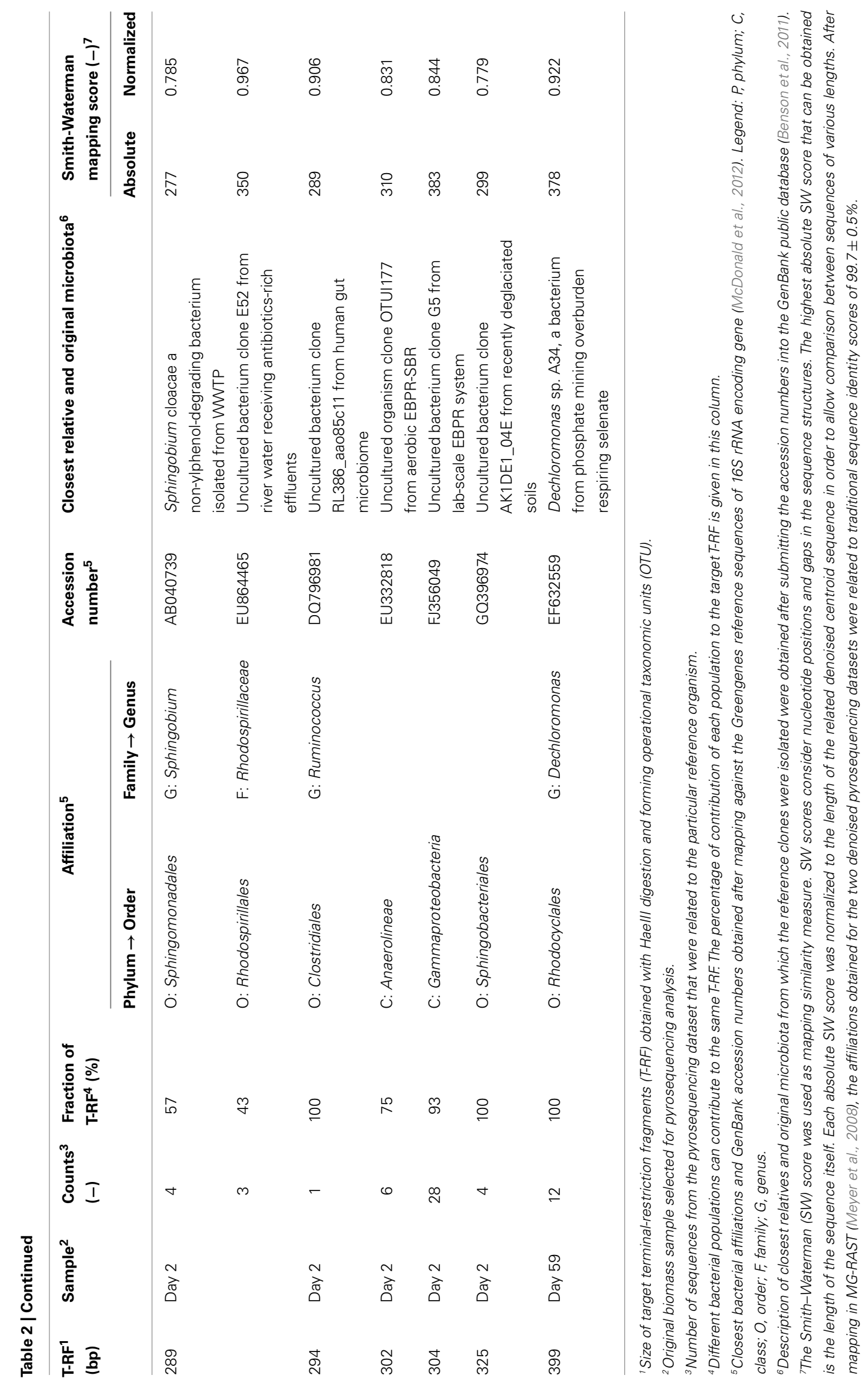


A

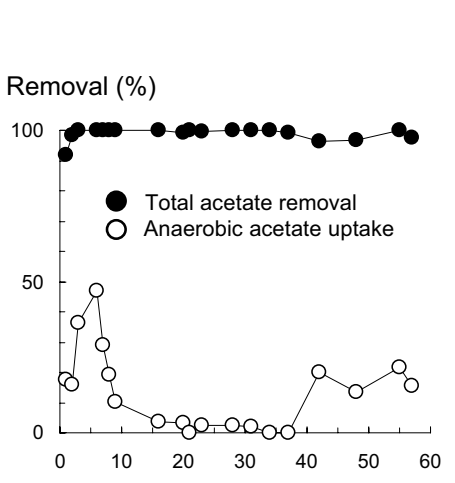

B

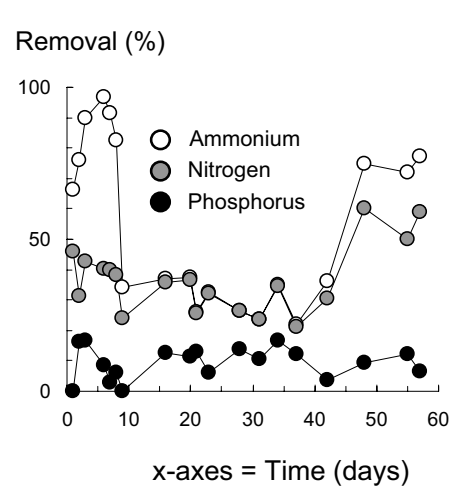

C Amount of orthophosphate $\left(\mathrm{mmol}_{\mathrm{P}-\mathrm{PO} 4}\right)$

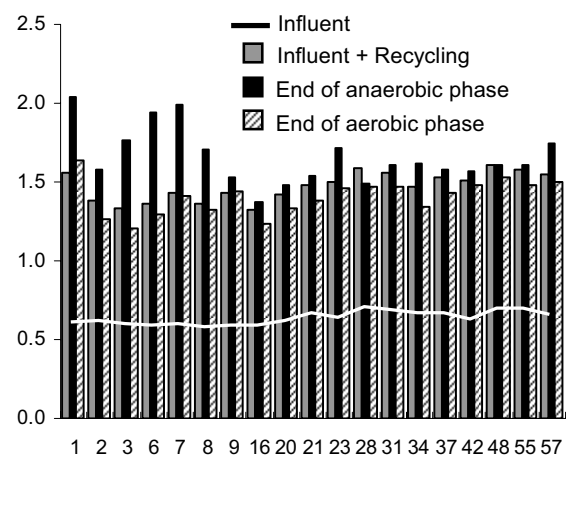

FIGURE 4 | Detailed evolution of the nutrient removal performances in reactor $\mathbf{R 6}$. The application of wash-out dynamics resulted in the transient loss of anaerobic acetate uptake (A), nitrification, nitrogen removal, and phosphorus removal performances (B) from day 6 to day 40. Orthophosphate cycling activities in alternating anaerobic-aerobic conditions were not detected during the same period (C).

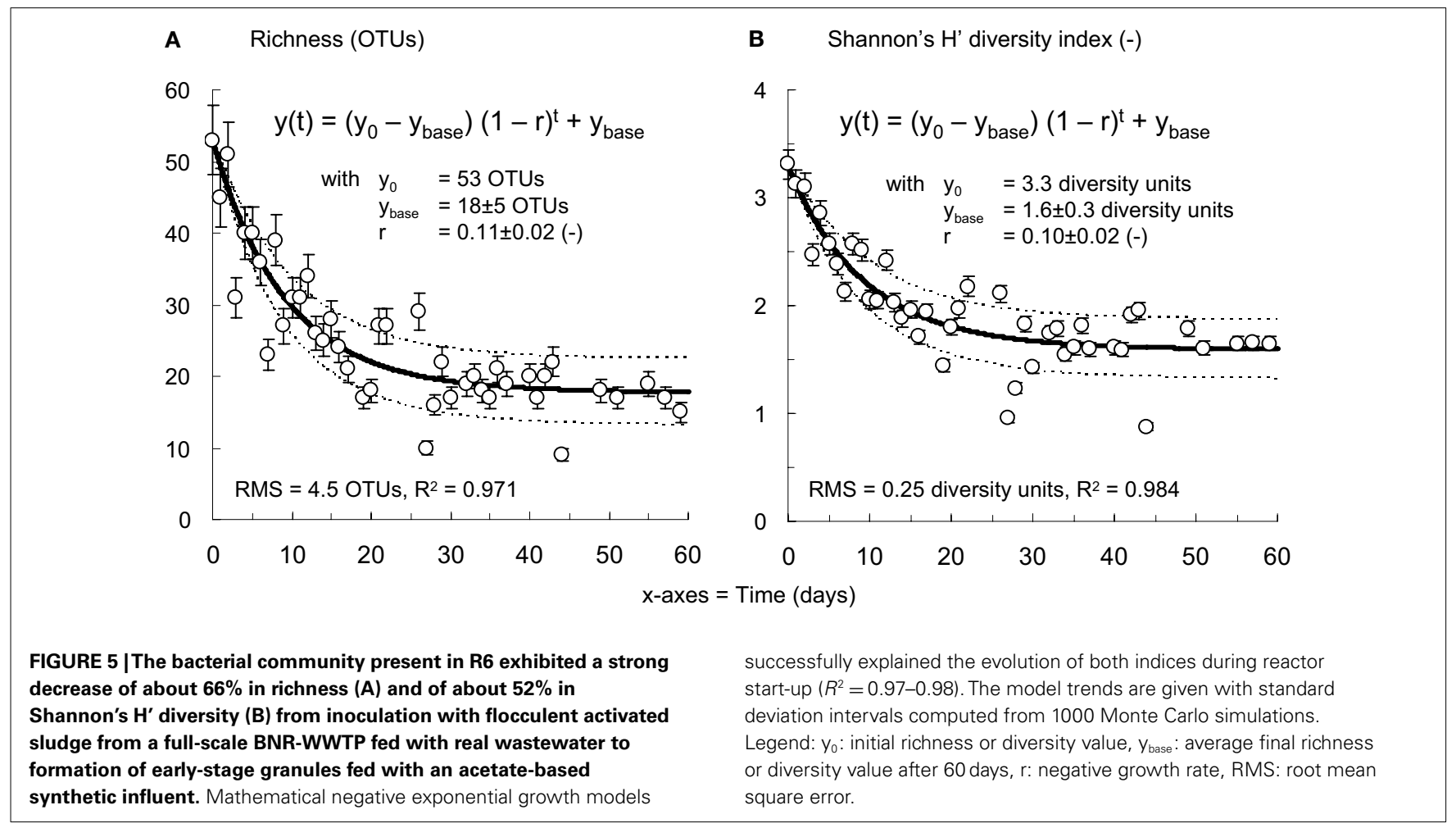

granules (day 30-60) was composed of $18 \pm 5$ OTUs, and showed a diversity index of $1.6 \pm 0.3$. The best fits of the mathematical geometric evolution models to the evolution of richness and diversity indices $\left(\mathrm{R}^{2}=0.97\right.$ and 0.98 , respectively) were obtained with finite rates of decrease of 11 and $10 \%$, respectively. According to the models, the decrease in richness and diversity before extensive biomass wash-out (day 0-8) amounted to 38 and $30 \%$, i.e., apparent decrease rates of about 2.5 OTUs and 0.13 diversity units per day. During the formation of early-stage granules occurring after biomass wash-out (day 8-27), the richness and diversity decreased by another 27 and 21\% (0.8 OTUs and 0.04 diversity units per day).

The pyrosequencing analyses of biomass samples collected on day 2 and day 59 confirmed that the early-stage AGS displayed a strongly reduced richness and diversity compared to the initial flocculent sludge (Table 3). The bacteriome of the flocculent sludge on day 2 was composed of 50 orders and 170 genera that were evenly distributed (3.9 diversity units). The bacteriome of the early-stage AGS was composed of only 20 orders and 57 genera that were unevenly distributed ( 1.1 diversity units). This 
Table 3 | Summary of the main bacterial orders and genera identified by pyrosequencing analysis of the flocculent sludge and early-stage AGS samples taken from $\mathbf{R 6}$.

\begin{tabular}{|c|c|c|}
\hline Main bacterial orders & $\%^{1}$ & Main bacterial genera and relative abundances \\
\hline Rhodocyclales & 24 & Zoogloea (10\%), Dechloromonas (9.7\%), Methyloversatilis (1.4\%), Azoarcus (1.3\%), Thauera (1.2\%) \\
\hline Burkholderiales & 9 & Acidovorax (3.7\%), Diaphorobacter (1.4\%), Burkholderia (1.2\%), Alcaligenes (0.7\%), Hydrogenophaga (0.4\%) \\
\hline Pseudomonadales & 9 & Acinetobacter $(8.0 \%)$, Pseudomonas $(0.7 \%)$ \\
\hline Bacillales & 6 & Brevibacillus (5.3\%), Trichococcus $(0.3 \%)$ \\
\hline Rhodobacterales & 5 & Azospirillum (2.0\%) \\
\hline Rhodospirillales & 3 & Rhodobacter (3.7\%), Rhodobaca (0.7\%) \\
\hline Rhizobiales & 2 & Methylosinus (1.1\%), Rhodopseudomonas (0.5\%), Methylocystis (0.3\%), Bradyrhizobiaceae (0.1\%) \\
\hline Sphingobacteriales & 2 & Terrimonas (1.3\%), Chitinophaga $(0.9 \%)$ \\
\hline Sphingomonadales & 2 & Sphingomonas (1.8\%) \\
\hline Burkholderiales & 4 & Massilia (2.5\%), Comamonas (0.5\%), Acidovorax (0.5\%) \\
\hline Flavobacteriales & 3 & Flavobacterium (2.8\%) \\
\hline Xanthomonadales & 2 & Stenotrophomonas (1.0\%), Pseudoxanthomonas (0.3\%), Dyella (0.2\%) \\
\hline Neisseriales & 2 & Aquitalea (1.4\%) \\
\hline 15 residual orders $(<2 \%)$ & 5 & 45 residual genera \\
\hline
\end{tabular}

${ }^{1}$ Relative abundances of bacterial orders obtained after mapping in MG-RAST (Meyer et al., 2008). Full bacteriome phylogenetic tree and sector graph representations are available in Figures $\boldsymbol{A 1 , A 2}$ in Appendix.

analysis also showed that the T-RFLP method was covering at least $85 \%$ of the diversity obtained by pyrosequencing. Within the Rhodocyclales order, Zoogloea affiliates became very predominant in the early-stage AGS, and Dechloromonas-related organisms that were abundant in the flocculent sludge at day 2 were replaced by Accumulibacter and Azoarcus relatives in the early-stage AGS at day 59.

At the level of the nitrifiers, the pyrosequencing analysis enabled detection of ammonium- $(\mathrm{AOB})$ and nitrite-oxidizing bacteria (NOB). AOB were only detected at relative abundances below $0.5 \%$ in the flocculent sludge, namely Nitrosococcus $(0.24 \%)$, Nitrosomonas (0.12\%), and Nitrosovibrio spp. (0.06\%), and represented a biomass concentration of $0.012 \mathrm{gVSS}^{-1}$. The NOB-related Nitrospira spp. were detected in higher abundance $(1.02 \%)$ than Nitrobacter spp. $(0.06 \%)$. The two genera together accounted for a biomass concentration of $0.032 \mathrm{gVsS}^{-1}$. The AOB and NOB present in the flocculent sludge were not detected in the earlystage granules. Only the AOB Nitrosospira spp. were detected at $0.03 \%$, and accounted for $0.002 \mathrm{gVSS} \mathrm{L}^{-1}$ on this particular day.

\section{DISCUSSION}

\section{FLUFFY AND DENSE FAST-SETTLING GRANULES HARBORED DIFFERENT PREDOMINANT PHYLOTYPES}

Unfavorable filamentous bulking occurring during early-stage granulation was related to the application of an insufficient SAV $\left(1.8 \mathrm{~cm} \mathrm{~s}^{-1}\right)$ in the case of an inoculum taken from OMR-WWTP, or when operation was conducted at higher mesophilic temperature $\left(30^{\circ} \mathrm{C}\right)$. The bacterial community of slowsettling fluffy granules was dominated by filamentous Sphaerotilus and Leptothrix bacterial genera. These organisms are known to cause severe filamentous bulking in conventional WWTPs (Richard et al., 1985). During the formation of compact flocs and granular biofilms, the proliferation of filamentous organisms toward the outside of microbial aggregates is enhanced by substrate gradients generated by diffusion limitations across the biofilm matrices (Martins et al., 2004; Liu and Liu, 2006). The ecology data showed that filamentous bulking can also occur with acetate as carbon source, and not only with carbohydrates that have been proposed as main bulking vectors (Liu and Liu, 2006).

The application of a more intensive $\operatorname{SAV}\left(4.0 \mathrm{~cm} \mathrm{~s}^{-1}\right)$ was successful for the recovery of smooth and dense fast-settling granules. In the study of McSwain et al. (2004), filamentous overgrowth was counteracted by high shear forces. In analogy to chlorine addition in conventional WWTPs, high shear forces helped to break the superficial filamentous structures. Specific remedial actions that suppress the cause of filamentous proliferation are however preferred for sustainable reactor operation (van Loosdrecht et al., 2008). The inoculation sludge taken from the BNR-WWTP was beneficial for the production of compact granules at $20^{\circ} \mathrm{C}$ with a low SAV. At full-scale level, this corresponds to definite energetic advantages. With the BNR-sludge, fluffy granules were only observed at $30^{\circ} \mathrm{C}$. The growth kinetics of filamentous bacteria are enhanced at such temperature (Richard et al., 1985). In BNRWWTPs, the successive anaerobic, anoxic, and aerobic zones are 
clearly separated. The readily biodegradable substrates are fully removed by $\mathrm{PAO}$ under anaerobic conditions, and are not available in the aerobic zone for fast-growing heterotrophs such as filamentous bacteria (van Loosdrecht et al., 2008). Thus, BNR-sludge exhibits a lower filamentous bulking potential than OMR-sludge, and can be advantageous for the granulation process. Ensuring full anaerobic acetate uptake in AGS-SBRs might also favorably suppress filamentous overgrowth.

Dense fast-settling early-stage aerobic granules were dominated by Zoogloea relatives. In contrast to fluffy and dense anaerobic granules that have been both dominated by Methanosaeta spp. (Grotenhuis et al., 1992; Hulshoff Pol et al., 2004), fluffy and dense aerobic granules were composed of different predominant phylotypes. Zoogloea spp. have also previously been detected in other granulation studies involving wash-out conditions (Etterer, 2006; Li et al., 2008; Ebrahimi et al., 2010; Gonzalez-Gil and Holliger, 2011).

\section{THE POSSIBLE ROLE OF RHODOCYCLALES-RELATED ORGANISMS IN GRANULATION}

The T-RFLP and metagenomics analyses revealed that Rhodocyclales-affiliated Zoogloea, Dechloromonas, Thauera, and Rhodocyclus spp. were abundant in the communities of fast-settling earlystage granules. Acinetobacter spp. were present during the transition from flocs to granules with anaerobic feeding. The Rhodocyclales-affiliated organisms share some physiological properties in BNR-WWTPs (Hesselsoe et al., 2009). They produce EPS and store poly- $\beta$-hydroxyalcanoates (PHA) when high organic loads are present under aerobic conditions, hold an arsenal of surface adhesins, and form flocs and biofilms (Sich and Van Rijn, 1997; Allen et al., 2004; Dugan et al., 2006; Oshiki et al., 2008; Nielsen et al., 2010; Seviour et al., 2012). Acetate was abundantly present under aerobic conditions due to pulse feeding, or to incomplete anaerobic uptake. Feast-famine regimes and high shear stress also stimulate EPS production during granulation (Liu and Tay, 2002; Dulekgurgen et al., 2008; Seviour et al., 2010). In contrast to flocculent sludge settling that can suffer from Zoogloea-mediated viscous bulking (Norberg and Enfors, 1982; van Niekerk et al., 1987; Lajoie et al., 2000), AGS settling was not hampered by the proliferation of Zoogloea relatives. High shear stress and compaction forces generated by up-flow aeration (Zima et al., 2007) were likely to counteract viscous bulking. In addition, storage compounds such as PHA confer higher density and settling velocity to bacterial cells (Mas et al., 1985; Schuler et al., 2001). PHA storage was confirmed by confocal laser scanning microscopy analysis with Nile Red staining of cross-sectioned granules dominated by Zoogloea spp. (data not shown). Hence, the physiology of Zoogloea-like and other Rhodocyclales-affiliated organisms might be relevant for the cohesion of granular biofilms. However, microbial aggregation is probably not restricted to single organisms, and specific process conditions could select for other organisms with similar functions (Bossier and Verstraete, 1996; Beun et al., 1999; Wang et al., 2009).

\section{WASH-OUT CONDITIONS AS DRASTIC BACTERIAL SELECTION PRESSURE DURING AEROBIC GRANULATION}

Even though inoculation with BNR-sludge and anaerobic feeding were combined, active PAO and nitrifiers were outcompeted by
Zoogloea spp. during start-up. Two tentative explanations of this specific bacterial selection were formulated from the results of R3R5 based on wash-out dynamics. Firstly, the wash-out dynamics resulted in an insufficient SRT that did not enable bacterial populations with lower growth rates such as PAO and nitrifiers to maintain themselves in the system. Secondly, during anaerobic feeding, the influent wastewater was not long enough in contact with the low residual biomass after wash-out. With a constant volumetric OLR and a fixed anaerobic plug-flow feeding phase, a large acetate fraction was present during aeration and selected for fastgrowing Zoogloea spp. over PAO. The data collected with R6 were used to confirm these explanations, and are discussed hereafter.

Tetrasphaera spp. and other Rhodocyclales-affiliated organisms such as Dechloromonas, Methyloversatilis spp., and Rhodocyclus spp. to a lower extent, were able to compete with Zoogloea spp. for the carbon source when $2.45 \mathrm{gVss} \mathrm{L}^{-1}$ and $30 \mathrm{~cm}$ of settled flocculent biomass was initially present in the system. By considering a bed porosity of 0.5 and an influent flow-rate of $21 \mathrm{~mL} \mathrm{~min}^{-1}$, each volume fraction of the influent wastewater was in contact with the settled biomass during $15 \mathrm{~min}$ on average. With this contact time, $50 \%$ of acetate was removed under anaerobic conditions with concomitant release of orthophosphate showing that PAO activity was still present. Accumulibacter was only present in low abundance in the flocculent sludge $(0.1-0.5 \%)$. However, additional organisms could have contributed to the detected PAO activity. Tetrasphaera spp. have been described as putative PAO in full-scale BNRWWTP, but their underlying dephosphatating metabolism has not yet been deciphered (Nielsen et al., 2012). Dechloromonas spp. have been described as an accompanying guild of Accumulibacter, and have been proposed as putative PAO as well (Kong et al., 2007; Oehmen et al., 2010). The genus Methyloversatilis that affiliates to Rhodocyclales has only recently been discovered, and has been shown to metabolize nitrogen (Kalyuzhnaya et al., 2006; Baytshtok et al., 2008; Kittichotirat et al., 2011). However, more research is required on its metabolism under alternating anaerobic-aerobic conditions.

The combination of a low settling time ( $3 \mathrm{~min}$ ) and a low HRT $(6 \mathrm{~h})$ resulted in intensive biomass wash-out. The SRT dropped to a value close to the HRT, and the reactor system was governed by the hydraulic properties. Aerobic heterotrophic organisms such as Zoogloea, Dechloromonas, Acinetobacter, and filamentous Burkholderiales affiliates that are related to maximum growth rates of 0.229-0.690 $\mathrm{h}^{-1}$ (Lau et al., 1984; van Niekerk et al., 1987; Logan et al., 2001; Kim and Pagilla, 2003) that are above 1/HRT, were able to proliferate over slower-growing PAO $\left(0.042 \mathrm{~h}^{-1}\right.$, Henze et al., 1999) and nitrifiers (0.017-0.046 $\mathrm{h}^{-1}$, Xavier et al., 2007). During reactor start-up, strong decreases in richness and diversity were observed. The apparent decrease rates were about 3 times higher before than after wash-out, indicating that the use of a synthetic wastewater with acetate as sole carbon source significantly contributed to the change in the bacterial community structure before wash-out. Gonzalez-Gil and Holliger (2011) have also reported that early-stage AGS cultivated with acetate or propionate as sole carbon and energy sources displayed half of the richness of the inoculation sludge. Winkler et al. (2011) have reported that, although distant, denaturing gradient gel electrophoresis profiles of bacterial communities of a conventional WWTP and of a pilot 
AGS reactor fed with the same urban wastewater exhibited similar richness and eveness.

After wash-out, only $0.3 \mathrm{gVss}^{-1}$ of biomass was remaining in the system and the biomass specific OLR increased by a factor of 13 from 51 to $685 \mathrm{mg}_{\mathrm{CODs}}$ cycle $^{-1} \mathrm{gCODx}^{-1}$. Granulation started with a biomass specific OLR above $2.7 \mathrm{kgCODs}^{-1} \mathrm{kgCODx}^{-1}$ equivalents, which is in agreement with the bottom value of $1.3 \mathrm{~kg}_{\mathrm{CODs}} \mathrm{d}^{-1} \mathrm{~kg}_{\mathrm{CODx}}{ }^{-1}$ considered by Morgenroth et al. (1997) to enable sludge granulation. However, with a settled biomass height of only $1 \mathrm{~cm}$, the contact time with the influent wastewater was extremely short (30 s). The fixed anaerobic plug-flow feeding phase thus resulted in the leakage of more than $90 \%$ of the acetate load into the aeration phase where it was available for fastgrowing aerobic heterotrophs. This also explains why Zoogloea spp. outcompeted Accumulibacter, and why phosphorus was not removed. Deteriorated dephosphatation has also been correlated in flocculent sludge SBRs with Zoogloea proliferation over PAO caused by the concomitant presence of acetate as electron donor and oxygen or nitrate as terminal electron acceptors (Fang et al., 2002; Montoya et al., 2008). Proper anaerobic selector operation has been recommended to suppress this zoogloeal overgrowth (van Loosdrecht et al., 2008).

In conclusion, the detailed microbial ecology investigation involving T-RFLP, pyrosequencing, and PyroTRF-ID analyses conducted in this study in combination with a bioprocess engineering approach showed that slow-settling fluffy granules and dense fast-settling early-stage granules cultivated under wash-out dynamics were displaying distinct predominant phylotypes, namely filamentous Burkholderiales affiliates and Zoogloea

\section{REFERENCES}

Adav, S. S., Lee, D. J., and Lai, J. Y. (2010). Microbial community of acetate utilizing denitrifiers in aerobic granules. Appl. Microbiol. Biotechnol. 85, 753-762.

Allen, M. S., Welch, K. T., Prebyl, B. S., Baker, D. C., Meyers, A. J., and Sayler, G. S. (2004). Analysis and glycosyl composition of the exopolysaccharide isolated from the floc-forming wastewater bacterium Thauera sp. MZ1T. Environ. Microbiol. 6, 780-790.

Baytshtok, V., Kim, S., Yu, R., Park, H., and Chandran, K. (2008). Molecular and biokinetic characterization of methylotrophic denitrification using nitrate and nitrite as terminal electron acceptors. Water Sci. Technol. 58, 359-365.

Benson, D. A., Karsch-Mizrachi, I., Lipman, D. J., Ostell, J., and Sayers, E. W. (2011). GenBank. Nucleic Acids Res. 39, D32-D37.

Beun, J. J., Heijnen, J. J., and van Loosdrecht, M. C. M. (2001). N-removal in a granular sludge sequencing batch airlift reactor. Biotechnol. Bioeng. 75, 82-92.

Beun, J. J., Hendriks, A., van Loosdrecht, M. C. M., Morgenroth, E., Wilderer, P. A., and Heijnen, J. J.
(1999). Aerobic granulation in a sequencing batch reactor. Water Res. 33, 2283-2290.

Bossier, P., and Verstraete, W. (1996). Triggers for microbial aggregation in activated sludge? Appl. Microbiol. Biotechnol. 45, 1-6.

Caporaso, J. G., Kuczynski, J., Stombaugh, J., Bittinger, K. Bushman, F. D., Costello, E. K., Fierer, N., Pena, A. G., Goodrich, J. K., Gordon, J. I., Huttley, G. A., Kelley, S. T., Knights, D., Koenig, J. E., Ley, R. E., Lozupone, C. A., McDonald, D., Muegge, B. D., Pirrung, M., Reeder, J., Sevinsky, J. R., Turnbaugh, P. J., Walters, W. A., Widmann, J., Yatsunenko, T., Zaneveld, J., and Knight, R. (2010). QIIME allows analysis of highthroughput community sequencing data. Nat. Methods 7, 335-336.

Cole, J. R., Wang, Q., Cardenas, E., Fish, J., Chai, B., Farris, R. J., KulamSyed-Mohideen, A. S., McGarrell, D. M., Marsh, T., Garrity, G. M., and Tiedje, J. M. (2009). The Ribosomal Database Project: improved alignments and new tools for rRNA analysis. Nucleic Acids Res. 37, D141-D145.

de Bruin, L. M. M., de Kreuk, M. K., van der Roest, H. F. R.,

relatives, respectively. Filamentous bulking could be remediated by the application of intensive up-flow aeration, or by the use of an inoculation sludge taken from a BNR-WWTP. A combination of insufficient SRT and of leakage of acetate into the aeration phase was the cause for the proliferation of Zoogloea spp. in dense fastsettling granules, and for the deterioration of BNR performances which has been commonly observed by different authors during granulation start-ups. It is however not certain that Zoogloea-like organisms are essential in granule formation. Additional research is needed to determine if they are required to stimulate early-stage granulation in BNR systems, or if granules can be cultivated without their involvement. Furthermore, optimal operation conditions should be elucidated for maintaining a balance between organisms with granulation propensity and nutrient removing organisms in order to form granules with BNR activities in short start-up periods.

\section{ACKNOWLEDGMENTS}

This research was financed by the Swiss National Science Foundation, Grant No. 205321-120536. David Weissbrodt obtained a grant from the EPFL FEE Foundation. We are grateful to ERM Morges and ARA Thunersee for providing the inoculation sludge. We recognize the excellent technical assistance of Sébastien Gabus, Jean-Pierre Kradolfer and Marc Deront in reactor operation, and of Corinne Weis, Yoan Rappaz and Emmanuelle Rohrbach in molecular ecology analyses. Scot E. Dowd, Yan Sun and Lars Koenig from the Research and Testing Laboratory (Lubbock, TX, USA) are acknowledged for pyrosequencing analyses and advice.

Uijterlinde, C., and van Loosdrecht, M. C. M. (2004). Aerobic granular sludge technology: an alternative to activated sludge? Water Sci. Technol. 49, 1-7.

de Kreuk, M. K., Heijnen, J. J., and van Loosdrecht, M. C. M. (2005). Simultaneous COD, nitrogen, and phosphate removal by aerobic granular sludge. Biotechnol. Bioeng. 90, 761-769.

Dugan, P., Stoner, D., and Pickrum, H. (2006). "The genus Zoogloea," in The Prokaryotes, eds M. Dworkin, S. Falkow, E. Rosenberg, K. H. Schleifer, and E. Stackebrandt (New York: Springer), 960-970.

Dulekgurgen, E., Artan, N., Orhon, D., and Wilderer, P. A. (2008). How does shear affect aggregation in granular sludge sequencing batch reactors? Relations between shear, hydrophobicity, and extracellular polymeric substances. Water Sci. Technol. 58, 267-276.

Ebrahimi, S., Gabus, S., RohrbachBrandt, E., Hosseini, M., Rossi, P. Maillard, J., and Holliger, C. (2010). Performance and microbial community composition dynamics of aerobic granular sludge from sequencing batch bubble column reactors operated at $20^{\circ} \mathrm{C}, 30^{\circ} \mathrm{C}$, and $35^{\circ}$ C. Appl. Microbiol. Biotechnol. 87, 1555-1568.

Etterer, T. J. (2006). Formation, Structure and Function of Aerobic Granular Sludge. Ph.D. thesis, Technische Universität München, Munich.

Fang, H. H. P., Zhang, T., and Liu, Y. (2002). Characterization of an acetate-degrading sludge without intracellular accumulation of polyphosphate and glycogen. Water Res. 36, 3211-3218.

Giesen, A., Niermans, R., and van Loosdrecht, M. C. M. (2012). Aerobic granular biomass: the new standard for domestic and industrial wastewater treatment? Water21 4, 28-30.

Gonzalez-Gil, G., and Holliger, C. (2011). Dynamics of microbial community structure and enhanced biological phosphorus removal of propionate- and acetate-cultivated aerobic granules. Appl. Environ. Microbiol. 77, 8041-8051.

Grotenhuis, J. T. C., Plugge, C. M., Stams, A. J. M., and Zehnder, A. J. B. (1992). Hydrophobicities and electrophoretic mobilities of anaerobic bacterial isolates from methanogenic granular sludge. Appl. Environ. Microbiol. 58, 1054-1056. 
Henze, M., Gujer, W., Mino, T., Matsuo, T., Wentzel, M. C., Marais, G. V. R., and Van Loosdrecht, M. C. M. (1999). Activated sludge model No.2d, ASM2d. Water Sci. Technol. 39, 165-182.

Hesselsoe, M., Fureder, S., Schloter, M., Bodrossy, L., Iversen, N., Roslev, P., Nielsen, P. H., Wagner, M., and Loy, A. (2009). Isotope array analysis of Rhodocyclales uncovers functional redundancy and versatility in an activated sludge. ISME J. 3, 1349-1364.

Hulshoff Pol, L. W., De Castro Lopes, S. I., Lettinga, G., and Lens, P. N. L. (2004). Anaerobic sludge granulation. Water Res. 38, 1376-1389.

Kalyuzhnaya, M. G., De Marco, P., Bowerman, S., Pacheco, C. C., Lara, J. C., Lidstrom, M. E., and Chistoserdova, L. (2006). Methyloversatilis universalis gen. nov., sp. nov., a novel taxon within the Betaproteobacteria represented by three methylotrophic isolates. Int. J. Syst. Evol. Microbiol. 56, 2517-2522.

Kim, H., and Pagilla, K. R. (2003). Competitive growth of Gordonia and Acinetobacter in continuous flow aerobic and anaerobic/aerobic reactors. J. Biosci. Bioeng. 95, 577-582.

Kittichotirat, W., Good, N. M., Hall, R., Bringel, F., Lajus, A., Médigue, C., Smalley, N. E., Beck, D., Bumgarner, R., Vuilleumier, S., and Kalyuzhnaya, M. G. (2011). Genome sequence of Methyloversatilis universalis FAM5 T, a methylotrophic representative of the order Rhodocyclales. J. Bacteriol. 193, 4541-4542.

Kong, Y., Xia, Y., Nielsen, J. L., and Nielsen, P. H. (2007). Structure and function of the microbial community in a full-scale enhanced biological phosphorus removal plant. Microbiology 153, 4061-4073.

Lajoie, C. A., Layton, A. C., Gregory, I. R., Sayler, G. S., Don, E. T., and Meyers, A. J. (2000). Zoogleal clusters and sludge dewatering potential in an industrial activated-sludge wastewater treatment plant. Water Environ. Res. 72, 56-64.

Lau, A. O., Strom, P. F., and Jenkins, D. (1984). Growth kinetics of Sphaerotilus natans and a floc former in pure and dual continuous culture. J. Water Pollut. Control Fed. $56,41-51$.

Lee, D.-J., Chen, Y.-Y., Show, K.-Y., Whiteley, C. G., and Tay, J.-H. (2010). Advances in aerobic granule formation and granule stability in the course of storage and reactor operation. Biotechnol. Adv. 28, 919-934.
Lemaire, R., Yuan, Z., Blackall, L. L., and Crocetti, G. R. (2008). Microbial distribution of Accumulibacter spp. and Competibacter spp. in aerobic granules from a labscale biological nutrient removal system. Environ. Microbiol. 10, 354-363.

Li, A. J., Yang, S. F., Li, X. Y., and $\mathrm{Gu}$, J. D. (2008). Microbial population dynamics during aerobic sludge granulation at different organic loading rates. Water Res. 42 , 3552-3560.

Lin, Y. M., Liu, Y., and Tay, J. H. (2003). Development and characteristics of phosphorus-accumulating microbial granules in sequencing batch reactors. Appl. Microbiol. Biotechnol. 62, 430-435.

Liu, Y., and Liu, Q.-S. (2006). Causes and control of filamentous growth in aerobic granular sludge sequencing batch reactors. Biotechnol. Adv. 24, 115-127.

Liu, Y., and Tay, J. H. (2002). The essential role of hydrodynamic shear force in the formation of biofilm and granular sludge. Water Res. 36, 1653-1665.

Logan, B. E., Zhang, H., Mulvaney, P., Milner, M. G., Head, I. M., and Unz, R. F. (2001). Kinetics of perchlorate- and chlorate-respiring bacteria. Appl. Environ. Microbiol. 67, 2499-2506.

Macey, R., Oster, G., and Zahnley, T. (2000). Berkeley Madonna User's Guide. Berkeley, CA: University of California.

Martins, A. M. P., Picioreanu, C., Heijnen, J. J., and van Loosdrecht, $\mathrm{M}$. C. M. (2004). Three-dimensional dual-morphotype species modeling of activated sludge flocs. Environ. Sci. Technol. 38, 5632-5641.

Mas, J., Pedros-Alio, C., and Guerrero, R. (1985). Mathematical model for determining the effects of intracytoplasmic inclusions on volume and density of microorganisms. J. Bacteriol. 164, 749-756.

McDonald, D., Price, M. N., Goodrich, J., Nawrocki, E. P., DeSantis, T. Z., Probst, A., Andersen, G. L., Knight, R., and Hugenholtz, P. (2012). An improved Greengenes taxonomy with explicit ranks for ecological and evolutionary analyses of bacteria and archaea. ISME J. 6, 610-618.

McSwain, B. S., Irvine, R. L., and Wilderer, P. A. (2004). The influence of settling time on the formation of aerobic granules. Water Sci. Technol. 50, 195-202.

Meyer, F., Paarmann, D., D’Souza, M., Olson, R., Glass, E., Kubal, M.,
Paczian, T., Rodriguez, A., Stevens, R., Wilke, A., Wilkening, J., and Edwards, R. (2008). The metagenomics RAST server - a public resource for the automatic phylogenetic and functional analysis of metagenomes. BMC Bioinformatics 9, 386. doi:10.1186/1471-2105-9386

Montoya, T., Borrás, L., Aguado, D., Ferrer, J., and Seco, A. (2008). Detection and prevention of enhanced biological phosphorus removal deterioration caused by Zoogloea overabundance. Environ. Technol. 29, 35-42.

Morgenroth, E., Sherden, T., van Loosdrecht, M. C. M., Heijnen, J. J., and Wilderer, P. A. (1997). Aerobic granular sludge in a sequencing batch reactor. Water Res. 31, 3191-3194.

Mosquera-Corral, A., de Kreuk, M. K., Heijnen, J. J., and van Loosdrecht, $M$. C. M. (2005). Effects of oxygen concentration on N-removal in an aerobic granular sludge reactor. Water Res. 39, 2676-2686.

Moy, B. Y. P., Tay, J. H., Toh, S. K., Liu, Y., and Tay, S. T. L. (2002). High organic loading influences the physical characteristics of aerobic sludge granules. Lett. Appl. Microbiol. 34, 407-412.

Nielsen, P. H., Mielczarek, A. T., Kragelund, C., Nielsen, J. L., Saunders, A. M., Kong, Y., Hansen, A. A., and Vollertsen, J. (2010). A conceptual ecosystem model of microbial communities in enhanced biological phosphorus removal plants. Water Res. 44, 5070-5088.

Nielsen, P. H., Saunders, A. M., Hansen, A. A., Larsen, P., and Nielsen, J. L. (2012). Microbial communities involved in enhanced biological phosphorus removal from wastewater - a model system in environmental biotechnology. Curr. Opin. Biotechnol. 23, 452-459.

Norberg, A. B., and Enfors, S. O. (1982) Production of extracellular polysaccharide by Zoogloea ramigera. Appl. Environ. Microbiol. 44, 1231-1237.

Oehmen, A., Carvalho, G., LopezVazquez, C. M., van Loosdrecht, M. C. M., and Reis, M. A. M. (2010). Incorporating microbial ecology into the metabolic modelling of polyphosphate accumulating organisms and glycogen accumulating organisms. Water Res. 44, 4992-5004.

Oksanen, J., Kindt, R., Legendre, P., O’Hara, B., Simpson, G. L., Solymos, P., Stevens, M. H. H., and Wagner, H. (2009). Vegan: Community Ecology
Package. Vienna: R Foundation for Statistical Computing.

Oshiki, M., Onuki, M., Satoh, H., and Mino, T. (2008). PHA-accumulating microorganisms in full-scale wastewater treatment plants. Water Sci. Technol. 58, 13-20.

Pijuan, M., Werner, U., and Yuan, Z. (2011). Reducing the startup time of aerobic granular sludge reactors through seeding floccular sludge with crushed aerobic granules. Water Res. 45, 5075-5083.

R-Development-Core-Team. (2008). R: A Language and Environment for Statistical Computing. Vienna: R Foundation for Statistical Computing.

Rees, G., Baldwin, D., Watson, G., Perryman, S., and Nielsen, D. (2004). Ordination and significance testing of microbial community composition derived from terminal restriction fragment length polymorphisms: application of multivariate statistics. Antonie Van Leeuwenhoek 86, 339-347.

Richard, M., Hao, O., and Jenkins, D. (1985). Growth kinetics of Sphaerotilus species and their significance in activated sludge bulking. J. Water Pollut. Control Fed. 57, 68-81.

Rossi, P., Gillet, F., Rohrbach, E., Diaby, N., and Holliger, C. (2009). Statistical assessment of variability of terminal restriction fragment length polymorphism analysis applied to complex microbial communities. Appl. Environ. Microbiol. 75, 7268-7270.

Schuler, A. J., Jenkins, D., and Ronen, P. (2001). Microbial storage products, biomass density, and setting properties of enhanced biological phosphorus removal activated sludge. Water Sci. Technol. 43, 173-180.

Seviour, T., Donose, B. C., Pijuan, M., and Yuan, Z. (2010). Purification and conformational analysis of a key exopolysaccharide component of mixed culture aerobic sludge granules. Environ. Sci. Technol. 44, 4729-4734.

Seviour, T., Yuan, Z., van Loosdrecht, M. C. M., and Lin, Y. (2012). Aerobic sludge granulation: a tale of two polysaccharides? Water Res. 46, 4803-4813.

Shin, H. S., Lim, K. H., and Park, H. S. (1992). Effect of shear stress on granulation in oxygen aerobic upflow sludge bed reactors. Water Sci. Technol. 26, 601-605

Sich, H., and Van Rijn, J. (1997). Scanning electron microscopy of biofilm formation in denitrifying, fluidised bed reactors. Water Res. 31, 733-742. 
Sun, Y., Wolcott, R. D., and Dowd, S. E. (2011). Tag-encoded FLX amplicon pyrosequencing for the elucidation of microbial and functional gene diversity in any environment. Methods Mol. Biol. 733, 129-141.

Tay, J. H., Liu, Q. S., and Liu, Y. (2002). Aerobic granulation in sequential sludge blanket reactor. Water Sci. Technol. 46, 13-18.

Tsuneda, S., Nagano, T., Hoshino, T., Ejiri, Y., Noda, N., and Hirata, A. (2003). Characterization of nitrifying granules produced in an aerobic upflow fluidized bed reactor. Water Res. 37, 4965-4973.

van Loosdrecht, M. C. M., Martins, A. M., and Ekama, G. A. (2008). "Bulking sludge," in Biological Wastewater Treatment: Principles, Modelling and Design, eds M. Henze, M. C. M. Van Loosdrecht, G. A. Ekama, and D. Brdjanovic (London: IWA Publishing), 291-308.

van Niekerk, A. M., Jenkins, D., and Richard, M. G. (1987). The competitive growth of Zoogloea ramigera and type $021 \mathrm{~N}$ in activated sludge and pure culture - a model for low F:M bulking. J. Water Pollut. Control Fed. 59, 262-273.

Verawaty, M., Pijuan, M., Yuan, Z., and Bond, P. L. (2012). Determining the mechanisms for aerobic granulation from mixed seed of floccular and crushed granules in activated sludge wastewater treatment. Water Res. 46, 761-771.

Wang, J., Zhang, Z., and Wu, W. (2009). Research advances in aerobic granular sludge. Acta Scientiae Circumstantiae 29, 449-473.

Weber, S. D., Ludwig, W., Schleifer, K. H., and Fried, J. (2007). Microbial composition and structure of aerobic granular sewage biofilms. Appl. Environ. Microbiol. 73, 6233-6240.

Winkler, M. K. H., Kleerebezem, R., de Bruin, L. M. M., Habermacher, J., Abbas, B., and van Loosdrecht, M. C. M. (2011). "Microbial diversity differences in aerobic granular sludge in comparison to conventional treatment plant," in IWA Biofilm Specialist
Conference, ed.Z.Qi(London: IWA), 23-26.

Xavier, J. B., de Kreuk, M. K., Picioreanu, C., and van Loosdrecht, M. C. M. (2007). Multi-scale individual-based model of microbial and byconversion dynamics in aerobic granular sludge. Environ. Sci. Technol. 41, 6410-6417.

Yilmaz, G., Lemaire, R., Keller, J., and Yuan, Z. (2008). Simultaneous nitrification, denitrification, and phosphorus removal from nutrient-rich industrial wastewater using granular sludge. Biotechnol. Bioeng. 100, 529-541.

Zima, B. E., Diez, L., Kowalczyk, W., and Delgado, A. (2007). Sequencing batch reactor (SBR) as optimal method for production of granular activated sludge (GAS) - fluid dynamic investigations. Water Sci. Technol. 55, 151-158.

Conflict of Interest Statement: The authors declare that the research was conducted in the absence of any commercial or financial relationships that could be construed as a potential conflict of interest.

Received: 10 August 2012; accepted: 27 August 2012; published online: 13 September 2012.

Citation: Weissbrodt DG, Lochmatter S, Ebrahimi S, Rossi P, Maillard and Holliger C (2012) Bacterial selection during the formation of early-stage aerobic granules in wastewater treatment systems operated under wash-out dynamics. Front. Microbio. 3:332. doi. 10.3389/fmicb.2012.00332

This article was submitted to Frontiers in Microbiotechnology, Ecotoxicology and Bioremediation, a specialty of Frontiers in Microbiology.

Copyright $\odot 2012$ Weissbrodt, Lochmatter, Ebrahimi, Rossi, Maillard and Holliger. This is an open-access article distributed under the terms of the Creative Commons Attribution License, which permits use, distribution and reproduction in other forums, provided the original authors and source are credited and subject to any copyright notices concerning any third-party graphics etc. 


\section{APPENDIX}

Composition of the cultivation media (Table A1). Cloning-sequencing databank constructed for OTUs detected in reactors R1R5 (Table A2). Full bacteriome phylogenetic tree constructed with the two pyrosequencing datasets (Figure A1). Sector graph representation of the bacteriome composition of the two bacteriomes of flocculent sludge and granular sludge (Figure A2).

Table A1 | Composition of the cultivation media, adapted from de Kreuk et al. (2005) and Ebrahimi et al. (2010).

\begin{tabular}{|c|c|c|c|c|c|}
\hline Compound & CAS no. & Molecular formula & $\begin{array}{l}\text { Molecular weight } \\
\left(\mathrm{g} \mathrm{mol}^{-1}\right)\end{array}$ & $\begin{array}{l}\text { Amount per } 20 \mathrm{~L} \\
\text { of medium }^{1}\end{array}$ & $\begin{array}{l}\text { Concentration in } \\
\text { medium (mmol L-1) }\end{array}$ \\
\hline \multicolumn{6}{|l|}{ Carbon source medium ${ }^{2}$} \\
\hline Magnesium sulfate & $7487-88-9$ & $\mathrm{MgSO}_{4} \cdot 7 \mathrm{H}_{2} \mathrm{O}$ & 246.51 & $17.75 \mathrm{~g}$ & 3.6 \\
\hline Potassium chloride & $7447-40-7$ & $\mathrm{KCl}$ & 74.55 & $7.16 \mathrm{~g}$ & 4.8 \\
\hline Dipotassium hydrogen phosphate & 7758-11-4 & $\mathrm{K}_{2} \mathrm{HPO}_{4}$ & 174.18 & $14.62 \mathrm{~g}$ & 4.2 \\
\hline Potassium dihydrogen phosphate & $7778-77-0$ & $\mathrm{KH}_{2} \mathrm{PO}_{4}$ & 136.09 & $5.72 \mathrm{~g}$ & 2.1 \\
\hline Trace element solution & - & - & - & $100 \mathrm{~mL}$ & - \\
\hline Compound & CAS no. & Molecular formula & $\begin{array}{l}\text { Molecular weight } \\
\left(\mathrm{g} \mathrm{mol}^{-1}\right)\end{array}$ & $\begin{array}{l}\text { Amount per } 5 \mathrm{~L} \text { of } \\
\text { stock solution }{ }^{1}(\mathrm{~g})\end{array}$ & $\begin{array}{l}\text { Concentration in stock } \\
\text { solution ( } \mathrm{mmol} \mathrm{L}^{-1} \text { ) }\end{array}$ \\
\hline Zinc sulfate & $7733-02-0$ & $\mathrm{ZnSO}_{4} \cdot 7 \mathrm{H}_{2} \mathrm{O}$ & 287.59 & 22.0 & 15.3 \\
\hline Calcium chloride & $10043-52-4$ & $\mathrm{CaCl}_{2} \cdot 2 \mathrm{H}_{2} \mathrm{O}$ & 147.02 & 81.8 & 111.3 \\
\hline Manganese chloride & $7773-01-5$ & $\mathrm{MnCl}_{2} \cdot 4 \mathrm{H}_{2} \mathrm{O}$ & 197.92 & 50.6 & 51.1 \\
\hline Iron(II) sulfate & 7720-78-7 & $\mathrm{FeSO}_{4} \cdot 7 \mathrm{H}_{2} \mathrm{O}$ & 278.05 & 49.9 & 35.9 \\
\hline Ammonium heptamolybdate & $12027-67-7$ & $\left(\mathrm{NH}_{4}\right)_{6} \mathrm{Mo}_{7} \mathrm{O}_{24} \cdot 4 \mathrm{H}_{2} \mathrm{O}$ & 1'235.88 & 16.4 & 2.7 \\
\hline Copper(II) sulfate & 7758-98-7 & $\mathrm{CuSO}_{4} \cdot 5 \mathrm{H}_{2} \mathrm{O}$ & 249.71 & 15.7 & 12.6 \\
\hline Cobalt(II) chloride & $7646-79-9$ & $\mathrm{CoCl}_{2} \cdot 6 \mathrm{H}_{2} \mathrm{O}$ & 237.96 & 16.1 & 13.5 \\
\hline
\end{tabular}

${ }^{1}$ The cultivation media and the trace element solution were prepared in 20 and $5 \mathrm{~L}$ of demineralized water.

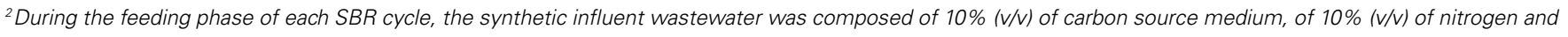
phosphorus source medium, and of $80 \%$ ( V/V) of tap water.

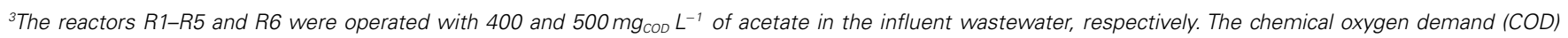
conversion factor of acetate is $64 \mathrm{~g}_{C O D} \mathrm{~mol}_{A C}{ }^{-1}$. 
Table A2 | Phylogenetic affiliation of predominant clones isolated from biomass samples of reactors R1-R5.

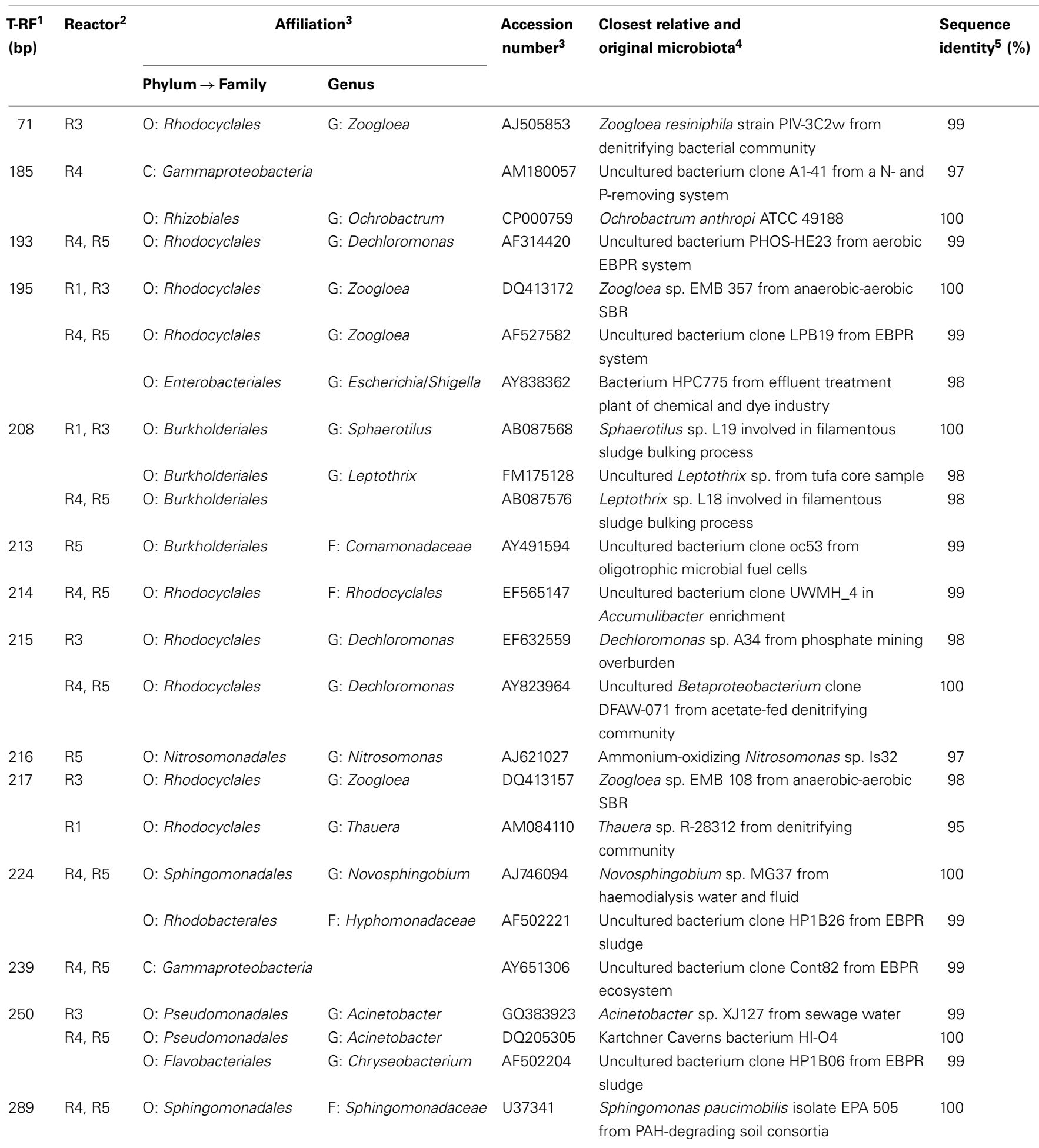

The initial cloning-sequencing database of Ebrahimi et al. (2010) was complemented in the present study.

${ }^{1}$ Size of target terminal-restriction fragments (T-RF) obtained with Haelll digestion and forming operational taxonomic units (OTU).

${ }^{2}$ Reactor biomass system from which the clones were isolated. A number of 1-7 clones were sequenced per T-RF.

${ }^{3}$ Closest bacterial affiliations and GenBank accession numbers obtain after mapping in the Ribosomal Database Project (RDP; Cole et al., 2009).

Legend: P, phylum; $C$, class; $O$, order; F, family; $G$, genus.

${ }^{4}$ Description of closest relatives and original microbiota from which the reference clones were isolated obtained from GenBank (Benson et al., 2011).

${ }^{5}$ Sequence identity scores obtained after mapping in RDP. 


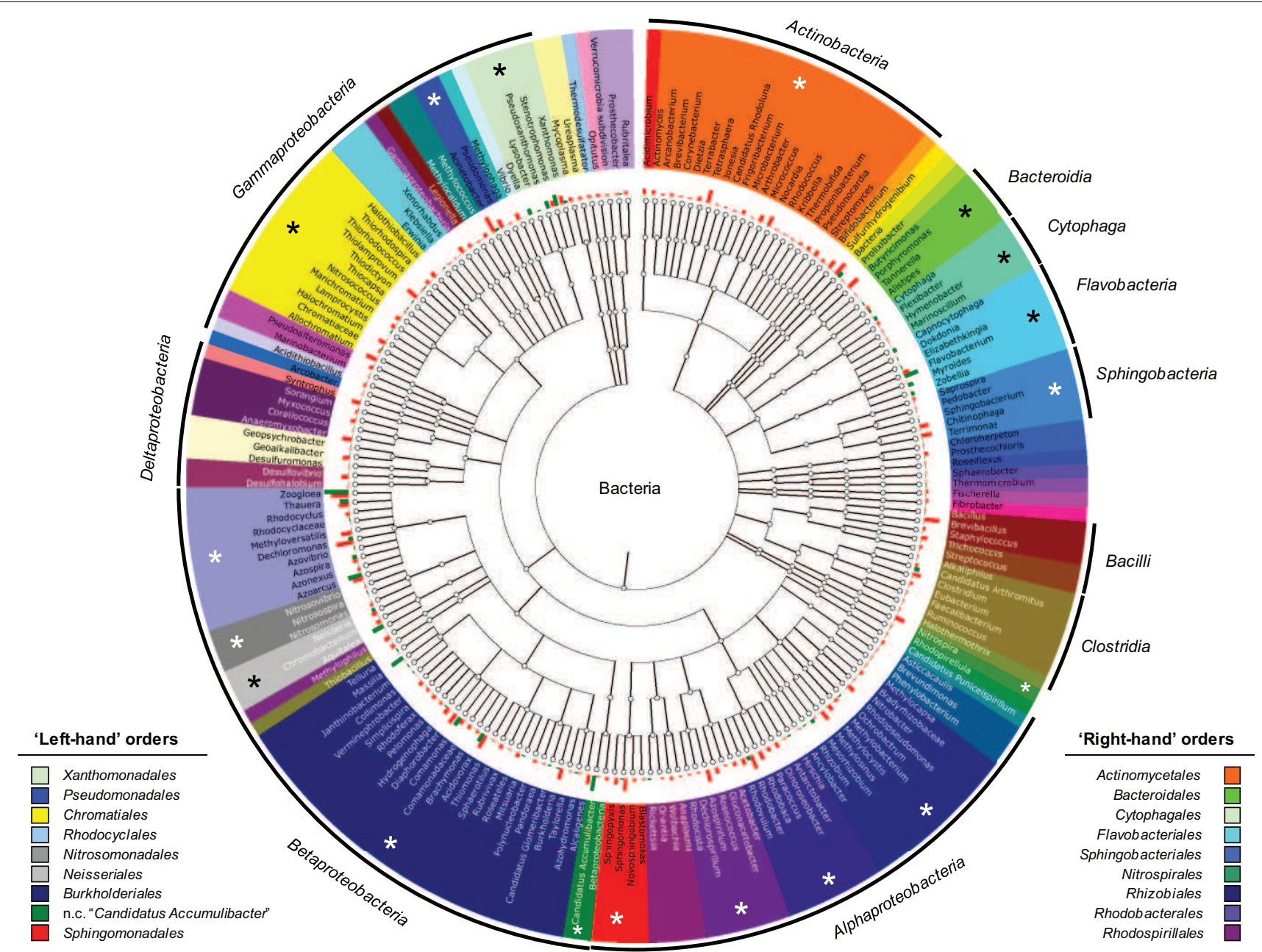

FIGURE A1 | Bacteriome phylogenetic tree constructed in MG-RAST (Meyer et al., 2008) with the pyrosequencing datasets of the two biomass samples collected on day 2 (flocculent sludge, red bar plot) and day 59 (early-stage AGS, green bar plot) in the $\mathbf{R} \mathbf{6}$ reactor. Each bar plot is related to the number of pyrosequencing reads detected per bacterial affiliation. The tree is presented with classes (outer black circle segments) and orders subdivisions (colored slices), and bacterial genera names. The identity of target orders marked with an asterisk is given for each left-hand and right-hand half of the circular tree. The RDP database (Cole et al., 2009) was used as annotation source, and a minimum identity cutoff of $97 \%$ was applied. 
A

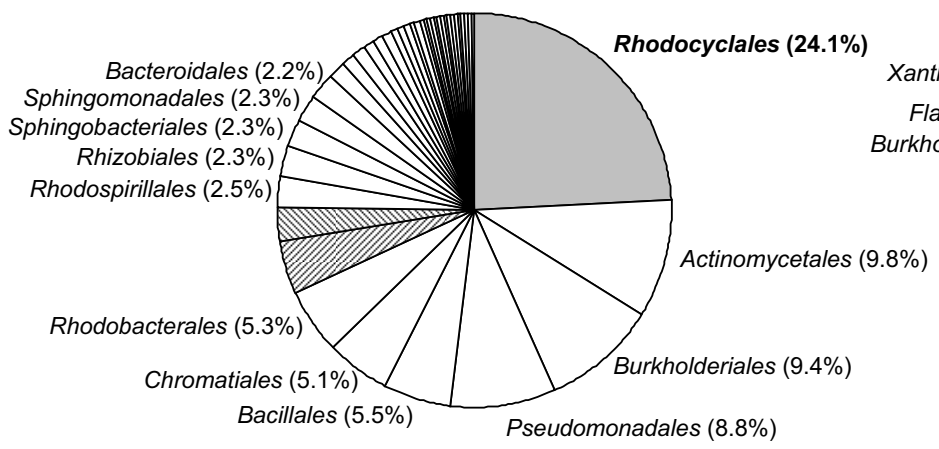

Early-stage granular sludge (day 59)

Neisseriales (1.5\%)

Xanthomonadales $(1.5 \%)$

Flavobacteriales (3.3\%)

Burkholderiales $(3.7 \%)$

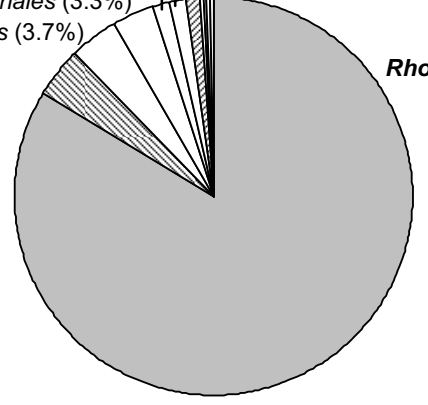

B

Flocculent sludge (day 2)

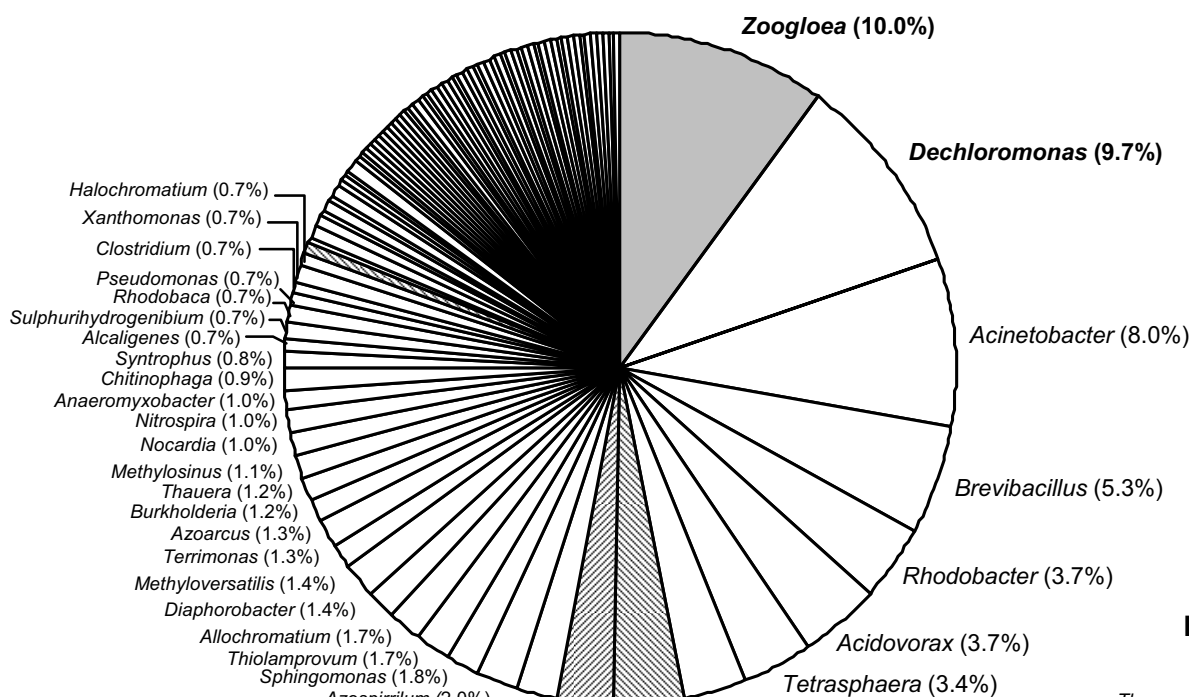

Sphingomonas $(1.8 \%)$

Azospirrilum $(2.0 \%$

Butyricimonas $(2.0 \%)$

Terrabacter $(3.2 \%)$

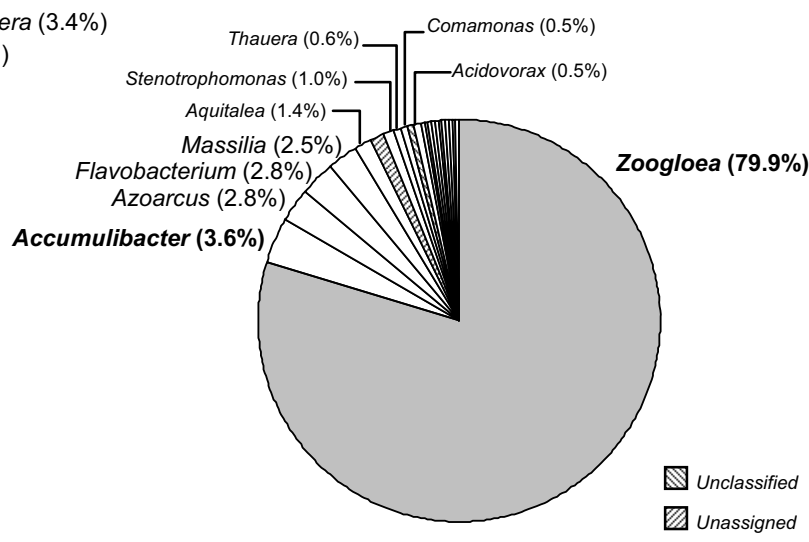

FIGURE A2 | Differences in the bacteriome composition of the flocculent sludge present in R6 before wash-out, and of the early-stage granular sludge present at day 59, at the order level (A) and at the genus level (B). 